\title{
La "judicialización”: una nueva característica del sistema jurídico internacional
}

\author{
The "Judicialization": a New Feature \\ of the International Legal System
}

\section{Virginia Petrova Georgieva*}

SUMARIO: I. Introducción. II. La multiplicación de los tribunales internacionales: un fenómeno reciente en el ámbito del derecho internacional. III. Las principales causas de la "judicialización" del orden jurídico internacional. IV. Los retos de la "judicialización” para el funcionamiento del sistema jurídico internacional. V. Conclusión. VI. Bibliografía.

* Doctoranda en Derecho Internacional en el Instituto de Investigaciones Jurídicas de la UNAM.

Artículo recibido el 25 de abril de 2014 Aprobado para publicación el 24 de septiembre de 2014 
RESUMEN: La multiplicación de los tribunales internacionales es un fenómeno reciente en el ámbito internacional. Durante la mayor parte de su historia, el orden jurídico internacional se caracterizaba por la insipiencia de los mecanismos judiciales de arreglo de las controversias. Debido a una serie de factores complejos, en la actualidad, dicho orden se ha "judicializado". El final de la Guerra Fría, la globalización de la economía, la extensión del campo de regulación ratione materiae y ratione personae de las normas internacionales, la creciente importancia de los actores no estatales en el ámbito de las relaciones internacionales y la relativización del carácter consensual de la justicia internacional propiciaron la creación de nuevas jurisdicciones internacionales. A pesar de sus múltiples efectos positivos, la “judicialización” suscita una serie de importantes retos para el funcionamiento del sistema jurídico internacional. Estos retos se relacionan, en particular, con la falta de relaciones estructurales entre los Tribunales internacionales y la especialización creciente de su función judicial respectiva.

Palabras clave: tribunales internacionales, multiplicación, especialización, coordinación.

ABSTRACT: The multiplication of the international tribunals is a recent phenomenon in the international level. During the major part of its history, the international legal system has been characterized by the insipience of the judicial settlement of disputes. As a consequence of some complex reasons, nowadays, this system is "judicialized”. The end of the Cold War, the globalization of the economy, the extension of the ratione materiae and ratione personae sphere of application of the international rules, the growing importance of the non-state actors in the international relations and the shift from the consensual character of the international justice has fostered the beginning and the development of the "judicialization" of the international legal system. This process has a lot of positive effects but it also creates some important challenges for the function of the international legal order. Those challenges rely, specially, on the lack of institutional links between the international tribunals and the growing specialization of their judicial function.

Key words: international tribunals, multiplication, specialization, coordination.

RÉSUMÉ: La multiplication des Tribunaux internationaux est un phénomène récent sur la scène internationale. Durand la plupart de son histoire, $\mathrm{l}^{\prime}$ ordre juridique international était caracterisé par l'incipience des mécanismes judiciaires de règlement des différends. Dans l'actualité, cet ordre s'est progressivement “juridictionnalisé” sous l'effet d'un certain nombre de facteurs complexes. La fin de la guerre froide, la globalisation de l'économie, $\mathrm{l}^{\prime}$ extension du champ d'application ratione materiae et ratione personae des normes internationales, l'importance croissante des acteurs non-étatiques dans les relations internationales et la relativisation du caractère consensuel de la justice internationale ont favorisé le surgissement et le développment de la "juridictionnalisation". Ce processus a beaucoup d'effets positifs mails il crée aussi un certain nombre de défis pour le fonctionnement armonieux de l'ordre juridique international. Ces défis résultent, en particulier, de l'absence de relations structurelles entre les différents Tribunaux internationaux et de la spécialisation croissante de leur fonction judiciaire respective.

Mots-clés: Tribunaux internationaux, multiplication, spécialisation, coordination. 


\section{INTRODUCCIÓN}

La multiplicación de los tribunales internacionales es un fenómeno reciente que sorprendió a muchos estudiosos del derecho internacional. Según Alexander Hamilton, los tribunales internacionales eran "el más débil de los tres poderes" en el sistema jurídico internacional. En la opinión de Michel Virally, "la debilidad del derecho internacional" siempre se había relacionado con la ausencia de un juez que resuelva las controversias entre los Estados miembros de la comunidad internacional. ${ }^{2}$

Estas opiniones doctrinales reflejaban una realidad histórica indiscutible. En efecto, la "debilidad" de los mecanismos judiciales de arreglo de los litigios caracterizó al derecho internacional por más de tres siglos. ${ }^{3}$ Durante la mayor parte de su existencia, el sistema jurídico internacional sufría notoriamente de la escasez, o incluso de la ausencia, de órganos judiciales imparciales. ${ }^{4}$ En consecuencia, muchos de los litigios internacionales se resolvían por medios alternativos (incluyendo el recurso a la fuerza) y el respeto del derecho internacional carecía de eficacia práctica.

Esta perspectiva cambió radicalmente en las dos últimas décadas. Ahora vivimos en una nueva era: la de la "judicialización" del sistema jurídico internacional. ${ }^{5} \mathrm{~A}$ partir de la década de los noventa se produjo una multiplicación (o proliferación ${ }^{6}$ ) sin precedente de tribunales internacionales. De tal modo que, en la actualidad, en el ámbito internacional, existen más

1 Hamilton, Alexander, “The Judiciary Department”, Independent Journal, 1788, p. 2, citado en Shany, Yuval, "No Longer a Weak Department of Power? Reflections on the Emergence of a New International Judiciary”, European Journal of International Law, vol. 20, 2009, p. 74.

2 Virally, Michel, Le droit international en devenir, PUF, 1990, p. 14.

3 Abi Saab, Georges Michel, "The Normalization of International Adjudication: Convergence and Divergence", International Law and Politics, vol. 43, 2010, pp. 1-4.

4 Ibidem, p. 5.

5 Cançado Trindade, Antonio Augusto, La expansión de la jurisdicción internacional y su realización de la justicia, UN Lecture Series, http://legal.un.org/avl/ls/Cancado-Trindade_HR_vi deo_2. Importancia para la html.

6 El término "proliferación" parece subrayar los efectos negativos de la "judicialización" del derecho internacional. Dicho término es utilizado, por ejemplo, en el ámbito militar para referirse a la proliferación de armas (nucleares, de destrucción masiva, químicas, etcétera). Por lo tanto, utilizaremos el término más neutro de "multiplicación” de los tribunales internacionales. 
de 50 órganos que cumplen con funciones de naturaleza judicial o casijudicial. ${ }^{7}$

La "judicialización” del orden jurídico internacional constituye un fenómeno reciente (II), propiciado por una serie de factores complejos (III). Dicho fenómeno suscita importantes retos para el funcionamiento del sistema jurídico internacional (IV), relacionados, en particular, con la coordinación entre los distintos tribunales internacionales y con la manera en la que éstos aplican e interpretan el derecho internacional. El análisis de los aspectos problemáticos de la actual “judicialización” del orden jurídico internacional debería ser el punto de partida para reflexionar sobre su posible resolución.

II. LA MULTIPLICACIÓN DE LOS TRIBUNALES INTERNACIONALES: UN FENÓMENO RECIENTE EN EL ÁMBITO DEL DERECHO INTERNACIONAL

Tradicionalmente se consideraba que la solución judicial de las controversias en el derecho internacional era insuficiente y poco desarrollada. Las vías tradicionales para el arreglo de dichas controversias eran las negociaciones diplomáticas y, excepcionalmente, el arbitraje internacional. ${ }^{8} \mathrm{El}$ contexto actual de la resolución de los litigios internacionales ha cambiado radicalmente.

A partir del final de la Segunda Guerra Mundial y, sobre todo, a partir de la década de los noventa, el sistema jurídico internacional se caracteriza por una multiplicación cada vez más creciente de órganos jurisdiccionales. El fenómeno de multiplicación de los tribunales internacionales es generalmente referido en la doctrina como "jurisdiccionalización" o "judicialización" y afecta a todas las esferas de regulación del derecho internacional.

7 Alford, Roger, "The Proliferation of International Courts and Tribunals: International Adjudication in Ascendance", American Journal of International Law, vol. 94, 2000, p. 160, cit. en Webb, Philippa, International Judicial Integration and Fragmentation, Oxford University Press, 2013, p. 1.

8 En particular porque estos dos métodos se consideraban mucho más respetuosos de la soberanía estatal que el sometimiento de los litigios a órganos judiciales internacionales.

9 La juridictionalisation du Droit International, Colloque de Lille, Société Francaise pour le Droit international, 2002, París, Pédone, 2003. 
Podemos distinguir varias etapas históricas en la evolución de los métodos judiciales de solución de controversias en el derecho internacional. ${ }^{10}$ Cronológicamente, las tres primeras etapas de su desarrollo se sitúan antes de 1989 y la cuarta etapa cubre el periodo de 1989 a la actualidad.

La historia moderna de los métodos de resolución de controversias en el derecho internacional ${ }^{11}$ comenzó con la adopción del "Tratado Jay" entre los Estados Unidos y Gran Bretaña en 1794. ${ }^{12}$ Los órganos creados por el "Tratado Jay" revivieron el interés por la utilización del arbitraje en el ámbito internacional. Durante todo el siglo XIX los Estados Unidos, Gran Bretaña y muchos otros Estados europeos recurrieron con frecuencia a este método de solución de las controversias. El arbitraje en el caso Alabama de 1872 marcó otro paso decisivo en el desarrollo de los mecanismos de arreglo de las diferencias en el derecho internacional. En el tratado de Washington, concluido en 1872 por los Estados Unidos y Gran Bretaña, los dos países acordaron someter sus principales litigios ${ }^{13}$ a un tribunal arbitral. ${ }^{14}$

10 Kebede Tiba, Firew, "What caused the multiplication of international Courts and Tribunals”, Gonzaga Journal of International Law, vol. 10, núm. 2, p. 203.

11 La solución de controversias en derecho internacional empezó a desarrollarse a partir del siglo XVIII. Como lo afirma Georges Abi-Saab (Abi-Saab, Georges, op. cit., pp. 2 y 3) previo a esta fecha regía el sistema resultante de la paz de Westphalia que ponía fin a las guerras de religión en Europa. Dicho sistema se caracterizaba por el establecimiento de relaciones internacionales, basadas en el principio de (formal) igualdad soberana entre los países europeos. Los "príncipes" europeos, que anteriormente debían obedecer a los Papas o Emperadores, reconocían mutuamente su autoridad suprema para definir la política interna e internacional de sus Estados. Esta estructura horizontal era muy poco favorable al desarrollo de órganos judiciales internacionales. Los soberanos eran muy renuentes a someter sus disputas a un tercero imparcial que les impusiera el respeto de una decisión fundada en reglas (jurídicas), por encima de su voluntad (soberana). Los pocos arreglos pacíficos de los litigios internacionales resultaban de un arbitraje inter pares: dos soberanos sometían su controversia a un tercero mediante el recurso a las negociaciones políticas (Abi-Saab, Georges, op. cit., p. 2).

12 El Tratado de Amistad, Comercio y Navegación fue concluido el 19 de noviembre de 1794 entre los gobiernos de los Estados Unidos y Gran Bretaña. Dicho Tratado fue nombrado "Jay Treaty" por el nombre del juez y exministro de relaciones exteriores de los Estados Unidos John Jay.

13 Dichas diferencias se referían a la falta de neutralidad de Gran Bretaña durante la Guerra Civil estadounidense, en particular porque la mayoría de los barcos de guerra que intervenían en el conflicto eran construidos y armados en puertos británicos. Tal era el caso del famoso barco “Alabama”. Cabe señalar que, en la actualidad, una importante sala en el Palacio de la Haya donde se encuentra la sede de la Corte Permanente de Arbitraje lleva precisamente este nombre.

14 Dicha observación era algo excepcional en una época en la que las principales controversias internacionales se arreglaban mediante el recurso a la fuerza. 
A partir de la Conferencia de Paz de la Haya, convocada por el tzar ruso Nikolaï II, comenzó una segunda fase en la historia moderna de los métodos de arreglo de diferencias en el derecho internacional. Al final de esta conferencia ${ }^{15}$ se adoptó una Convención para la Solución Pacífica de las Controversias Internacionales. ${ }^{16}$ Dicho tratado contenía disposiciones innovadoras, relativas al arbitraje y a los demás mecanismos de arreglo de los conflictos internacionales. Para facilitar su funcionamiento concreto, la Convención previó la creación de una Corte Permanente de Arbitraje (CPA) que empezó a funcionar a partir de 1902. Dicho órgano reunía un panel de juristas designados por cada país miembro de la Convención que podría ser utilizado para la constitución de los tribunales arbitrales en las controversias futuras. ${ }^{17}$ Por lo tanto, a diferencia de lo que su nombre indica, la CPA no era un verdadero órgano jurisdiccional..$^{18}$ No obstante, su creación constituyó una importante etapa en la institucionalización de los métodos de solución de las controversias internacionales y abrió el camino para la consolidación de las reglas jurídicas que los gobiernan. ${ }^{19}$

En la segunda Conferencia de Paz de la Haya de 1907 se adoptaron algunas modificaciones a la Convención de 1899 y se presentaron varias propuestas tendientes a mejorar el funcionamiento de la CPA.

Las ideas expresadas durante las dos Conferencias de Paz de la Haya sirvieron de inspiración para el establecimiento del primer tribunal internacional permanente al final de la Primera Guerra Mundial. Dichas ideas se materializaron en la adopción del Estatuto de la Corte Permanente de Justicia Internacional (CPJI) por la primera Asamblea de la Liga de las Na-

15 El objetivo principal de esta conferencia era discutir sobre el establecimiento de la paz y el desarmamiento a nivel internacional.

16 El nombre mismo de la Convención indica la concepción que se tenía de la resolución de las controversias internacionales. El adjetivo "pacífica” es utilizado para contrastar con el principal método de arreglo de los conflictos en esta época: el recurso a la fuerza (Abi, Saab, op. cit., p. 3).

17 Desde este punto de vista el objetivo de la Convención era facilitar el funcionamiento del arbitraje (o constituir una arbitration faclity). (Swebel, Stephen, The Merits (and Demerits) of International Arbitration and Adjudication, Un Lecture Series, http: / / untreaty.un.org/cod/avl/ls / Schwebel_CT_video_1.html).

18 Como lo afirma Abi Saab, la CPA no era ni Corte, ni permanente. (Abi Saab, Georges, The International Judicial Function, UN Lecture Series, http://untreaty.un.org/cod/avl/ls/ Abi-Saab_CT_video_1.html).

19 http://www.icj-cij.org/court/index.php?p1 $=1 \& p 2=1$. 
ciones $^{20}$ en diciembre de 1920. Por primera vez en su historia, el orden jurídico internacional fue dotado de una jurisdicción independiente de las partes en una controversia internacional.

El comienzo de la Segunda Guerra Mundial interrumpió la actividad de la CPJI y la solución (pacífica) de las controversias en el derecho internacional fue suspendida por completo. Después del final de la guerra, en octubre de 1944, en la Conferencia de Dumberton Oaks y Yalta, las cuatro potencias vencedoras se pusieron de acuerdo sobre los objetivos, la estructura y el funcionamiento de una nueva organización mundial de Estados: la Organización de las Naciones Unidas (ONU). Posteriormente, durante la Conferencia de San Francisco, ${ }^{21}$ en abril de 1945, se decidió crear la Corte Internacional de Justicia (CIJ) como uno de los principales órganos de la ONU y anexar su Estatuto a la Carta constitutiva de dicha organización. El Estatuto de la CIJ fue basado en el Estatuto de su predecesora, la $\mathrm{CPJI}^{22}$ y esta última fue formalmente disuelta en enero de $1946 .{ }^{23}$

Según Kebede Tiba, ${ }^{24}$ la creación de la CIJ en 1946 marcó una tercera etapa en el desarrollo de los métodos de arreglo de diferencias en el derecho internacional. El establecimiento de la primera jurisdicción internacional permanente fue seguido por la creación de otros tribunales con competencia regional o universal. El estatuto de la CIJ sirvió de inspiración

20 La Liga de la Naciones también denominada Sociedad de las Naciones (SDN) era una organización de Estados establecida por iniciativa del presidente de los Estados Unidos, Woodrow Wilson, con el objetivo de evitar futuras guerras internacionales y garantizar la paz a nivel mundial. Su sede era en Ginebra y su funcionamiento debía permitir la resolución pacífica de las controversias entre sus Estados parte. Poco después de su creación, la SDN fracasó, y años más tarde dio origen a la actual Organización de las Naciones Unidas (ONU).

21 La Conferencia de San Francisco fue una de las mayores Conferencias internacionales de la época, visto que contó con la participación de 50 Estados.

22 Además, la sede de la CIJ también fue fijada en el Palacio de la Paz en la Haya y ésta empezó a funcionar con muchos de los funcionarios de la CPJI, incluyendo el primer presidente de la CIJ y último presidente de la CPJI, el salvadoreño José Gustavo Guerrero.

23 Una de las principales razones para crear una nueva Corte internacional y no mantener o reformar la CPJI fue la percepción de esta última como parte de un viejo orden mundial. En efecto, muchos de los Estados miembros de la Comunidad internacional consideraban que la CPJI representaba un orden mundial en el que los países europeos ejercían su dominación cultural, política, económica, etcétera. En cambio, con la creación de la ONU se intentaba poner fin a los viejos imperialismos y se buscaba encontrar un equilibrio más multipolar en el ámbito de las relaciones internacionales.

24 Kebede Tiba, Firew, op. cit., p. 203. 
para la adopción de varios otros tratados constitutivos de jurisdicciones internacionales permanentes.

Así, en los años 1950 y 1960, en el ámbito regional europeo fueron creados dos nuevos tribunales internacionales: el Tribunal de Justicia de las Comunidades Europeas ${ }^{25}$ (TJCE) y la Corte Europea de Derechos Humanos $(\mathrm{CEDH})$.

La CEDH fue creada en 1959 para velar por el respeto de la Convención Europea de Derechos por parte de los Estados miembros del Consejo de Europa. A partir de su creación, la CEDH se ha convertido en uno de los tribunales internacionales más activos y su jurisprudencia desempeña una función sumamente importante para el desarrollo del derecho internacional de los derechos humanos. Por su parte, los Tratados de Roma establecieron el Tribunal de Justicia de las Comunidades Europeas (TJCE), órgano judicial único para las tres comunidades. ElTJCE muy pronto adquirió una importancia fundamental para el funcionamiento de la integración regional europea. ${ }^{26}$ Aun en la actualidad el TJUE es frecuentemente considerado como uno de los tribunales internacionales "más influyentes del mundo". ${ }^{27}$

Cabe señalar que el final de la Guerra Fría también creó la necesidad de repensar los problemas económicos y financieros internacionales, con el objetivo de relanzar la reconstrucción económica de los países. En este sentido, fueron concluidos los acuerdos de Bretton Woods que crearon el Banco Mundial y el Fondo Monetario Internacional. ${ }^{28}$ La recuperación de las relaciones comerciales internacionales en los años siguientes fomentó el desarrollo de las inversiones extranjeras a nivel global. Por consecuencia, fue necesario adoptar una regulación jurídica de los flujos de inversiones en el ámbito internacional. En 1965, bajo los auspicios del Banco Mundial, fue

25 A partir de la entrada en vigor del Tratado de Lisboa en 2009, el TJCE se denomina Tribunal de Justicia de la Unión Europea (TJUE).

26 Simon, Denis, Le système juridique communautaire, 3a. ed., París, PUF, 2001, p. 206.

27 La jurisprudencia del Tribunal tuvo una contribución crucial para el desarrollo tanto de la integración en el orden jurídico comunitario como de la integración regional europea, en su conjunto. En efecto, las sentencias del TJUE establecieron los principios fundamentales del derecho de la UE, a pesar de que éstos no estaban previstos en los tratados originarios.

28 Los acuerdos de Bretton Woods son las resoluciones de la Conferencia Monetaria y Financiera de las Naciones Unidas, realizada en el complejo hotelero de Bretton Woods, New Hampshire, entre el 1o. y el 22 de julio de 1944. En dicha conferencia se fijaron las reglas económicas y financieras que debían regir las relaciones entre los países industrializados de la época y se optó por el establecimiento de una política económica liberal a nivel internacional. 
elaborada la Convención de Washington para el Arreglo de Controversias sobre Inversiones. ${ }^{29}$ Dicha Convención estableció el Centro Internacional para el Arreglo de Controversias sobre Inversiones (CIADI).$^{30}$ El CIADI permite la resolución de las controversias entre inversionistas y Estados miembros de la Convención de Washington mediante el recurso al arbitraje institucional. ${ }^{31}$

Así, hasta los principios de los años 1980, el número de jurisdicciones internacionales se había multiplicado considerablemente en comparación con el estado de desarrollo de los métodos de solución de controversias a principios del siglo XX. La principal causa de la creación de nuevos tribunales internacionales en este periodo fue el establecimiento de un nuevo orden mundial al final de la Segunda Guerra Mundial. Las necesidades de reconstrucción económica, garantía a la paz y el restablecimiento de las relaciones internacionales en la época de la posguerra propiciaron la creación de nuevas jurisdicciones, competentes para resolver los litigios de derecho internacional que se presentaban. No obstante, el número de tribunales internacionales establecidos de 1902 a 1989 no superaba $7 .{ }^{32}$ Una aceleración sin par del fenómeno de "judicialización” del derecho internacional ocurrió en la década de los noventa.

La cuarta etapa de desarrollo de los métodos de solución de controversias en el derecho internacional inició en los años 1990. A partir de 1989 y hasta la actualidad asistimos a una multiplicación sin precedente de los tribunales internacionales. En este corto periodo de tiempo fueron creadas o completamente reformadas más de 12 jurisdicciones internacionales. ${ }^{33}$

29 La Convención fue adoptada por el Banco Mundial el 18 de marzo de 1965 y entró en vigor el 14 de octubre de 1966 después de haber sido ratificada por 20 Estados. Esta participación creció de manera importante, en particular durante los años noventa. En 2002 el número de Estados miembros a la Convención llegó a ser 135.

30 History of the ICSID Convention, http: / / icsid.worldbank.org/ICSID / FrontServlet? request Type= CasesRH\&actionVal=ShowHome\&pageName=AboutICSID_Hom.

31 La institucionalización del arbitraje CIADI tenía como objetivo facilitar la resolución de las controversias en materia de inversiones y promover un clima favorable para su desarrollo a nivel internacional.

32 En efecto, hasta 1990 en el ámbito internacional operaban únicamente seis jurisdicciones internacionales: la CIJ, la CEDH, la CIDH, el TJUE, el CIADI y elTJCA.

33 En particular, el Tribunal penal para la ex-Yugoslavia, el Tribunal Penal para Ruanda, la Corte Penal Internacional, el sistema de solución de las controversias de la OMC, el del TLCAN, el del Mercosur, la Corte de Justicia del Caribe, la Corte de Justicia de la Comesa, 
En la actualidad pueden ser identificadas 20 jurisdicciones internacionales (tribunales o comisiones) permanentes y, al menos, otras 17 instituciones internacionales que cumplen con funciones de naturaleza judicial o casijudicial. ${ }^{34}$ Podemos pensar en los nuevos tribunales internacionales competentes en materia de derecho del comercio internacional o de derecho internacional de las inversiones, en las jurisdicciones competentes en materia de derechos humanos o en las que aplican el derecho penal internacional. ${ }^{35}$

Esta multiplicación cuantitativa de las jurisdicciones internacionales fue acompañada por un cambio cualitativo en su naturaleza y funciones respectivas. Por ejemplo, en la actualidad, la mayoría de las jurisdicciones internacionales son competentes para resolver controversias no únicamente de carácter interestatal sino también controversias en las que intervienen actores no estatales (organizaciones internacionales gubernamentales o no gubernamentales, personas físicas o morales). De la misma manera, mientras que la mayoría de las jurisdicciones establecidas antes de 1990 tenían competencia universal, hoy día asistimos al desarrollo de jurisdicciones que intervienen a nivel regional y son mucho más influenciadas por los contextos jurídicos propios de cada región. ${ }^{36}$ Además, en los últimos veinte años observamos la creación de categorías completamente nuevas de jurisdicciones: los tribunales penales internacionales o los tribunales mixtos, a la vez internos e internacionales. ${ }^{37}$

el Tribunal Internacional para el Derecho del Mar, la Corte Especial para Sierra Leona y las jurisdicciones establecidas en el ámbito de: la Comisión Africana para los Derechos Humanos y de los Pueblos, la Comisión de Compensaciones de las Naciones Unidas, la Asociación Europea de Libre Comercio, la Organización para la Seguridad y la Cooperación en Europa.

34 Romano, Cesare, Project on International Courts and Tribunals, trad. de Omar Carrasco y Juan Andrés Alvarez, Center on International Cooperation, New York University, 2004-2005.

35 Bodack, Jessica, "International Law for the Masses", Duke Journal of Comparative and International law, vol. 15, p. 364.

36 Romano, Cesare, "The Proliferation of International Judicial Bodies: the Pieces of the Puzzle", International Law and Politics, vol. 31, 1999 p. 710.

37 En la actualidad existen varios Tribunales mixtos, establecidos para juzgar crímenes y delitos graves cometidos en el territorio de algunos países. Con este objetivo fueron establecidos el Tribunal internacional para Timor Oriental, el Tribunal para Irak y los Tribunales mixtos para juzgar los khmer rouge de Cambodia. Los Tribunales mixtos "confiscan" la competencia de los Tribunales internos para asegurar la protección de algunos de los intereses fundamentales de la Comunidad internacional. 
Podemos preguntarnos cuáles fueron los factores que causaron estos cambios tan importantes en la naturaleza y alcance de la resolución de las controversias en el derecho internacional.

\section{LAS PRINCIPALES CAUSAS DE LA “JUDICIALIZACIÓN” DEL ORDEN JURÍDICO INTERNACIONAL}

La multiplicación sin par de jurisdicciones internacionales es el resultado de una serie de factores complejos. Sin pretender a la exhaustividad podemos mencionar algunos de ellos. El final de la Guerra Fría (1), la globalización y la regionalización de la economía mundial (2), la extensión del campo de regulación material del derecho internacional (3), la creciente importancia de los actores no estatales en el ámbito de las relaciones internacionales (4) y la relativización del carácter consensual de la justicia internacional (5) propiciaron de manera importante la multiplicación de los tribunales internacionales.

\section{El final de la Guerra Fría}

El final de la Guerra Fría tuvo por efecto la multilateralización de las relaciones internacionales y el abandono de las teorías marx-leninistas como fundamento teórico-filosófico para la conducta de dichas relaciones. Estos dos procesos crearon una necesidad funcional de establecer nuevas jurisdicciones internacionales. A partir de la desintegración de la Unión Soviética fueron establecidos al menos 10 nuevos tribunales internacionales. Así, por ejemplo, la creación en 1993 de un tribunal penal internacional para juzgar los crímenes de guerra cometidos en el territorio de la exYugoslavia fue el resultado indirecto del final del bipolarismo. ${ }^{38}$ El consenso internacional que acompañó su creación y el éxito con el que funciona el Tribunal Penal para la exYugoslavia influenciaron su reproducción para el caso de los

38 En efecto, el establecimiento de este Tribunal se decidió por un consensos entre todos los Estados miembros del Consejo de Seguridad de la ONU. Además dicha creación fue sin duda propiciada por el cambio radical en la posición de la ex Unión Soviética respecto a la soberanía política de los Estados de Europa del Sur-este (Romano, Cesare, op. cit., p. 714). 
crímenes internacionales cometidos durante el genocidio en Ruanda. Posteriormente, estos dos primeros tribunales penales internacionales sirvieron de inspiración para la creación de una Corte Penal Internacional permanente por el Estatuto de Roma en 2003. Otro ejemplo importante de la influencia que ejerció el final del bipolarismo sobre la multiplicación de los mecanismos de solución de controversias en derecho internacional puede ser hallado en materia de derechos humanos. El desarrollo del multilateralismo en la escena internacional propició la adhesión de nuevos miembros al Consejo Europeo de Derechos Humanos ${ }^{39}$ y orientó la reestructuración de la Corte Europea de Derechos Humanos en 1994.40

La caída de la "Cortina de Hierro" también condujo a la imposición del modelo económico-liberal como paradigma dominante en el ámbito internacional. Este modelo permitió la liberalización progresiva de los intercambios comerciales internacionales y el incremento de los flujos económicos y financieros a la escala global. En particular, el éxito del capitalismo como modelo económico, propició el desarrollo de dos fenómenos paralelos: la "globalización” y la "regionalización” de la economía mundial.

\section{La globalización y la regionalización de la economía mundial}

La globalización es generalmente considerada como un proceso de integración creciente de la economía mundial cuyos catalizadores principales son la liberalización de los intercambios internacionales y de los movimientos de capitales, la aceleración del proceso tecnológico y la supresión de las fronteras estatales. ${ }^{41}$ En otros términos, se trata de un:

Proceso de internalización del capital financiero, industrial y comercial, resultado del surgimiento de la empresa trasnacional, que se basa en el avance y desarrollo de la tecnología porque ha facilitado su extensión en la interacción entre las nacio-

39 Principalmente tratándose de los Estados de Europa central y oriental.

40 La adhesión de los nuevos miembros del Consejo de Europa creó la necesidad de modificar varios artículos de la Convención Europea de Derechos Humanos y subsecuentemente reformar el funcionamiento del órgano jurisdiccional que ésta establece. En particular, fue necesario ampliar las funciones jurisdiccionales de la CEDH y las vías directas de acceso a su foro.

${ }_{41}$ Frison-Roche, Marie-Anne, "Droit international économique et mondialisation”, Les grandes questions du droit économique, París, Quadrige-PUF, 2005, p. 69. 
nes originando profundas consecuencias económicas, políticas y culturales tanto a nivel nacional como internacional. ${ }^{42}$

La "globalización" de la economía mundial tuvo un efecto "catalizador" para la "judicialización” del derecho internacional. La regulación de las nuevas actividades generadas por la globalización exigió la adopción de normas internacionales específicas. Posteriormente, la aplicación e interpretación de estas normas fueron confiadas a tribunales internacionales especializados.

Por ejemplo, la regulación del comercio internacional iniciada con la creación de la Organización Mundial del Comercio (OMC) en 1994, necesitó el establecimiento de un mecanismo original de solución de las controversias para interpretar y aplicar las Convenciones Relativas a las Relaciones Comerciales Multilaterales. ${ }^{43}$ Por su parte, el desarrollo del comercio internacional fomentó la multiplicación de los flujos inversionistas a nivel global. La adopción de las normas que fundamentan el derecho internacional de las inversiones favoreció la creación de foros jurisdiccionales internacionales, competentes para resolver los litigios en esta materia. Podemos pensar en el arbitraje bajo los auspicios del Centro Internacional para el Arreglo de Controversias sobre Inversiones (CIADI), en el arbitraje internacional ad hoc, en el arbitraje bajo los auspicios de la Comisión de las Naciones Unidas para el Derecho Comercial Internacional (CNUDMI) o en el arbitraje organizado por la Cámara del Comercio Internacional (CCI) de París.

El desarrollo de la globalización propició el surgimiento de un proceso paralelo de "regionalización" o "regionalismo". Este proceso se basa en la proximidad geográfica de sus integrantes y tiene como objetivo principal la promoción de las relaciones comerciales entre los países vecinos. Un punto común indudable que comparten todas las integraciones regionales consiste en haberse dotado de un mecanismo específico para la solución de

42 Segrelles, José Antonio, “Integración regional y globalización”, Terra livre, vol. 18, 2002, p. 68.

43 El sistema de solución de conflictos en el ámbito de la OMC inició como un arbitraje comercial confiado a paneles ad hoc y evolucionó hacia un verdadero sistema jurisdiccional, en particular, después del establecimiento de un segundo grado de jurisdicción confiado a un órgano de apelación. La importancia de algunos asuntos tratados por el mecanismo de solución de controversias de la OMC le atribuye una función creciente en el funcionamiento eficaz del sistema comercial multilateral. 
las controversias que surgen de la interpretación o aplicación del derecho regional.

Así, desde la creación de las Comunidades europeas, actualmente unificadas en la Unión Europea, se consideró necesario establecer un tribunal independiente e imparcial para la interpretación y la aplicación del derecho comunitario: el Tribunal de Justicia de la Unión Europea (TJUE). La creación del tribunal europeo influenció la concepción de los mecanismos de solución de controversias en las integraciones regionales vigentes en otras áreas geográficas. En este sentido, en el ámbito geográfico latinoamericano fueron establecidos tribunales internacionales competentes para resolver las controversias suscitadas por el funcionamiento de las integraciones regionales que rigen en dicho contexto. ${ }^{44}$ Por ejemplo, el arreglo de las controversias en la Comunidad Andina de Naciones (CAN) es confiado al Tribunal de Justicia de la Comunidad Andina (TJCA), ${ }^{45}$ la Corte del Caribe es competente para resolver las disputas entre los Estados miembros de la Comunidad del Caribe (Caricom) y la Corte Centroamericana de Justicia para las del Mercado Común Centroamericano (MCCM). Aparte la creación de una corte permanente, en las integraciones latinoamericanas también existen ejemplos de órganos arbitrales ad hoc, especialmente constituidos para el arreglo de las diferencias entre los Estados miembros de la integración. En particular, el régimen de solución de controversias vigente en el Mercado Común del Sur (Mercosur) es de naturaleza arbitral. La misma naturaleza intergubernamental caracteriza la resolución de las controversias en el ámbito del Tratado de Libre Comercio de América del Norte (TLCAN).

44 Las integraciones regionales latinoamericanas son: la Comunidad Andina de Naciones (CAN) que integran Bolivia, Colombia, Ecuador y Perú, el Mercado Común del Sur (Mercosur) entre Argentina, Brasil, Paraguay y Uruguay (cabe señalar que a partir de 2006 Venezuela se retiró de la CAN e inició su procedimiento de adhesión al Mercosur), la Comunidad del Caribe (Caricom) conformada por 15 Estados de la región caribeña (Antigua y Barbuda, Bahamas, Barbados, Belice, Dominica, Granada, Guyana, Haiti, Jamaica, Montserrat, Santa Lucía, San Cristóbal y nieves, San Vicente y las Granadinas, Surinam, Trinidad y Tobago) y el Mercado Común Centroamericano (MCCA) que reúne a Costa Rica, El Salvador, Guatemala, Honduras y Nicaragua. Todas estas integraciones son dotadas de un mecanismo específico de resolución de las controversias que surgen entre sus Estados miembros.

45 Cabe señalar que el TJCA constituye una reproducción muy fiel del TJUE en el ámbito andino. La intención de "clonar" el TJUE aparece claramente en las disposiciones normativas que regulan la estructura y el funcionamiento del TJCA. En efecto, el juez andino fue dotado de una estructura y competencias contenciosas completamente idénticas a las del juez europeo. 
Otro ejemplo de tribunales internacionales especialmente establecidos para regular el funcionamiento jurídico de las integraciones regionales se encuentra en el contexto africano. ${ }^{46}$ En efecto, en el continente africano operan dos tribunales internacionales con competencia regional: la Corte de Justicia del Mercado Común de África Austral y Oriental y la Corte de Justicia de la Unión del Magreb Árabe. A pesar de su carácter permanente, dichas jurisdicciones no desempeñan una función activa en el desarrollo de sus integraciones regionales respectivas.

En la actualidad existe una sola región integrada que no cuenta con un mecanismo judicial para la solución de las controversias que surjan entre sus países miembros. En efecto, la mayoría de los países asiáticos son miembros de la Asociación de los Estados del Sureste Asiático (ASEAN por sus siglas en inglés) que todavía no se ha dotado de un tribunal internacional permanente.

La creación de tribunales en el ámbito de las integraciones regionales y el desarrollo de nuevas jurisdicciones internacionales, competentes para regular los conflictos que surgen como resultado de la globalización económica, acentúan de manera importante la "judicialización" del derecho internacional. Estos fenómenos se relacionan muy estrechamente con otro factor que impulsa la multiplicación de las jurisdicciones internacionales: la "expansión" reciente del derecho internacional en nuevos ámbitos de regulación normativa.

\section{La extensión del campo de regulación material del derecho internacional}

El derecho internacional es generalmente visto como el resultado de una producción normativa de origen interestatal. Dicho en otros términos, se considera que la mayoría de las normas internacionales provienen de un consentimiento que los Estados miembros de la comunidad internacional

46 En el ámbito africano existen dos integraciones regionales: el Mercado Común de África Austral y Oriental (Comesa por su abreviación en inglés) entre 20 países africanos (Burundi, Comoras, República Democrática de Congo, Yibuti, Egipto, Eritrea, Etiopía, Kenia, Libia, Madagascar, Malaui, Ruanda, Seychelles, Sudán, Sudán del Sur, Uganda, Suazilandia, Zambia, Zimbabue) que, contrariamente a lo que su nombre indica, constituye una simple unión aduanera y la Unión del Magreb Árabe (Arab Maghreb Union) entre Marruecos, Argelia, Túnez, Mauritania y Libia. 
expresan en varios instrumentos jurídicos de naturaleza intergubernamental (tratados, convenios, líneas directrices, etcétera). No obstante, en la actualidad esta constatación ya no es válida. Como lo afirma $\mathrm{RaO}^{47}$ el alcance y la estructura del derecho internacional han cambiado. Las normas internacionales son susceptibles de crear derechos y obligaciones para los Estados miembros de la comunidad internacional sin, o incluso en contra de, su voluntad. Además, los Estados ya no son los únicos actores que pueden crear normas internacionales. ${ }^{48}$

Por otra parte, las nuevas actividades generadas por la globalización exigieron la adopción de normas internacionales para regular sus distintos campos de desarrollo. Por más de 400 años el derecho internacional constituía un cuerpo normativo relativamente "pobre". Las normas internacionales regulaban algunos problemas en el ámbito de las relaciones internacionales, por ejemplo, la conducta de los diplomáticos, los conflictos marítimos o la integridad territorial de los Estados. ${ }^{49}$ En la actualidad, existen muy pocas esferas de las relaciones internacionales fuera del alcance de las normas jurídicas internacionales. Esta “juridización” de las relaciones internacionales vuelve el campo regulatorio del derecho internacional casi omnipresente. Además, no solo se ha incrementado la producción de las normas internacionales. Su contenido también se vuelve cada vez más heterogéneo. En efecto, el surgimiento de nuevos ámbitos de desarrollo de las relaciones internacionales propició la creación de regímenes normativos especializados.

En este sentido, la necesidad de proteger los derechos humanos de los individuos de las distintas violaciones cometidas a nivel nacional o tras-

47 Rao, Pemmaraju Sreenivasa, "Multiple Judicial Forums: a Reflections of the Growing Strengh of International Law or its Fragmentation”, Michigan Journal of International Law, vol. 25, 2004, p. 939.

48 El desarrollo de organizaciones de Estados, especializadas en distintas materias del derecho internacional (económico, humanitario, cultural etcétera) implica la aparición de nuevos centros de producción normativa. La importancia de los actores no estatales (individuos o empresas trasnacionales) en la esfera de las relaciones internacionales se suma a este fenómeno. La lex mercatoria y la diversidad de normas internacionales adoptadas para regular la actividad de los miembros de la Sociedad civil internacional favorece la aparición de una "inflación normativa” en el derecho internacional. En consecuencia, la construcción del sistema normativo del derecho internacional se torna polícentrica y multi-niveles.

49 Burke-White, William, "International Legal Pluralism”, Michigan Journal of International Law, vol. 25, 2004, p. 967. 
nacional condujo a la adopción de múltiples normas internacionales en esta materia. Dichas normas son aplicables a nivel, tanto regional, como universal, y su importante desarrollo en las últimas décadas permitió el surgimiento de un verdadero sistema internacional de protección de los derechos humanos.

A la protección de los derechos humanos en tiempos de paz se suma su cautela en tiempos de guerra. La necesidad de salvaguardar los derechos de las víctimas de crímenes y delitos cometidos durante los conflictos armados exigió la adopción de normas penales internacionales. Las normas que forman parte del derecho penal internacional adquieren cada vez mayor madurez y conducen a la consolidación de otro régimen normativo específico en el ámbito internacional: el derecho penal internacional.

Esta extensión del campo de regulación material del derecho internacional también puede observarse en el ámbito económico. La liberalización cada vez mayor de los intercambios comerciales internacionales y la internalización del capital financiero crean nuevas actividades en la esfera internacional. Su regulación exige la adopción de normas especializadas en materia económica. El desarrollo fulminante de este nuevo campo normativo creó el cuerpo autónomo de las normas del derecho internacional económico. ${ }^{50}$

Tanto el derecho internacional de los derechos humanos, como el derecho penal internacional y el derecho internacional económico son ejemplos de la creación de conjuntos normativos especializados y distintos (a primera vista) unos vis-à-vis de los otros y vis-à-vis del derecho internacional general. Estos nuevos campos de regulación normativa del derecho internacional orientaron la creación de órganos jurisdiccionales competentes para aplicar sus regímenes especializados. Como lo afirma PierreMarie Dupuy ${ }^{51}$ la expansión del derecho internacional puede ser explicada conforme a las leyes físicas: a más densidad normativa corresponden más conflictos internacionales y por ende se incrementa la necesidad de

50 Por su parte, el derecho internacional económico puede dividirse en varios subsistemas normativos: derecho del comercio internacional, derecho internacional de las inversiones, derecho internacional de la competencia y derecho internacional financiero. En los años recientes todas estas materias se imparten como disciplinas autónomas en muchas de las universidades del mundo.

51 Dupuy, Pierre-Marie, “The Danger of Fragmentation or Unification of the International Legal System and the International Court of Justice”, International Law and Politics, 1999, p. 792. 
crear instituciones jurisdiccionales, competentes para resolverlos. Dicho en otros términos, cuanto más complejo y sofisticado se vuelve el orden internacional, tanto más sus integrantes necesitan de la intervención de un tercero imparcial para resolver sus controversias. ${ }^{52}$

La naturaleza cada vez más específica de los campos de aplicación ratione materiae, ratione personae y ratione loci de las normas internacionales exige conocimientos cada vez más especializados por parte de las instituciones encargadas de aplicarlas e interpretarlas. La falta de "expertise" por parte de los tribunales internacionales "clásicos", como por ejemplo la CIJ, justificó el establecimiento de nuevas jurisdicciones especializadas en los nuevos ámbitos de producción de normas internacionales. ${ }^{53}$ Como lo afirma la juez Higgins, la especialización creciente de las normas internacionales y la descentralización de algunas de sus materias exigió la creación de tribunales internacionales, altamente especializados, cuyos miembros son expertos en relación con los problemas complejos que se presentan en los litigios internacionales. ${ }^{54}$

Así, el desarrollo del sistema internacional de protección de los derechos humanos se relaciona con la institución de tribunales internacionales cuya misión exclusiva se refiere precisamente a la protección de estos derechos que forman parte del patrimonio jurídico de todo individuo. De la misma manera, el desarrollo del derecho penal internacional fue a la vez el resultado y el vector del establecimiento de las nuevas jurisdicciones penales internacionales.

La aceleración de la globalización comercial, la creación de integraciones regionales de Estados y la descentralización en la adopción del derecho internacional después de la Guerra Fría extendieron no solo el campo de aplicación ratione materiae sino también el campo de aplicación ratione personae del derecho internacional. Los Estados ya no son los únicos afectados por las normas internacionales. ${ }^{55}$ La actual sociedad internacional se

52 Dupuy, Pierre-Marie, op. cit., p. 806.

53 Cabe señalar que estas críticas son dirigidas en especial a la CIJ que se considera como "insuficiente" para resolver las controversias cada vez más complejas que oponen a los integrantes del orden jurídico internacional.

54 Higgins, Rosalyn, "Respecting the Sovereign States and the Running a Tight Courtroom”, International and Comparative Law Quarterly, 2001, p. 122.

55 Reed, Lucy, "Great Expectations: Where Does the Proliferation of International Dis- 
caracteriza por una participación cada vez más creciente de los actores no estatales en la aplicación y desarrollo del derecho internacional. Dicha participación es otro factor que nos permite explicar la multiplicación de las jurisdicciones en el ámbito internacional. ${ }^{56}$

\section{La importancia de los actores no estatales en el ámbito de las relaciones internacionales}

Los actores no estatales adquieren una importancia creciente en el funcionamiento de la actual sociedad internacional. ${ }^{57}$ La evolución del Derecho internacional en las últimas décadas se caracteriza por una pérdida del monopolio estatal sobre las relaciones internacionales. ${ }^{58}$ Como lo afirma Mireille Delmas-Marty, la visión (moderna) del orden jurídico internacional como un orden, compuesto exclusivamente por Estados, ${ }^{59}$ está cediendo ante una nueva concepción (posmoderna) de dicho orden. ${ }^{60}$ En este orden, los Estados han sido "atacados" en sus atributos principales: el Esta-

pute Resolution Tribunals Leave International Law?", American Society of International Law and Procedure, vol. 19, 2002, pp. 219-221.

56 Bodack, Jessica, op. cit., p. 365.

57 Como lo afirma Klabbers, el orden jurídico internacional se está “verticalizando”: ya no se trata de un orden horizontal que regula las relaciones mutuas entre Estados (únicamente) sino de un orden "vertical" de múltiples sistemas y subsistemas en los que intervienen múltiples actores (Klabbers, Jan et al., The Constitutionalization of International Law, Oxford University Press, 2011, p. 14).

58 No obstante, cabe señalar que la función cada vez más importante de los actores no estatales en el funcionamiento de la actual Sociedad internacional no pone fin a la participación estatal en el ámbito de las relaciones internacionales. Los Estados siguen siendo los sujetos prima facie del derecho internacional y su rol en la construcción y consolidación del orden jurídico internacional no debe de ser menospreciado.

59 Como lo afirma Klabbers, la visión tradicional del orden jurídico internacional consideraba a este como una mesa de billar sobre la que interactuaban los Estados, a la imagen de bolas de billar, transparentes e iguales. (Klabbers, Yan et al., op. cit., p. 14).

60 Como lo afirma Friedmann, estamos pasando de un derecho internacional de coordinación (entre los Estados) a un derecho internacional de cooperación (entre los distintos sujetos de la Comunidad internacional) (Friedmann, Wolfgang, The Changing Structure of International Law, Columbia University Press, 1964, p. 60, cit. en Shany, Yuval, "One Law to Rule Them All: Should International Courts be Viewed as Guardians of Procedural Order and Legal Uniformity?", en Fauchald, Ole Kristian y Nollkaemper, André (eds.), The Practice of International and National Courts and the (De-)Fragmentation of International Law, Hart Publishing, 2012 , p. 18). 
do (legislador) "centralizado" ha sido afectado por la descentralización de los centros internacionales de producción normativa, el "Estado-nación" como expresión de una "comunidad" de intereses, ha sufrido "erosiones" de soberanía por su participación en "comunidad(es) internacional(es)” y, finalmente, el Estado de las "esferas públicas” ha sido debilitado por la "privatización” del derecho internacional. ${ }^{61}$ En la opinión de Delmas-Marty, el término "privatización" (privatisation) ${ }^{62}$ se refiere a la distinción entre los sujetos del derecho público (en particular los Estados y/o sus representantes, encargados de defender y promover el interés público general) y los sujetos del derecho privado (que defienden sus intereses particulares). Debido a los recientes cambios y a la "complexificación" del orden jurídico internacional, este último ya cuenta con sujetos, tanto públicos, como privados. ${ }^{63}$ El desarrollo de cuerpos normativos especializados ha vuelto las personas privadas y/o empresas transnacionales actores activos en el ámbito de las relaciones internacionales. Los actores privados son sujetos de la aplicación de normas internacionales (en particular, las relativas a la protección de los derechos humanos, al derecho penal internacional o al derecho internacional económico) pero también autores de tales normas (por ejemplo, las pertenecientes a la lex mercatoria o a algunas categorías del soft law). La importancia creciente de los actores no estatales en la "escena internacional” también se hace palpable en el surgimiento y resolución de las controversias internacionales.

En efecto, tanto las organizaciones internacionales, como los actores privados (individuos o empresas trasnacionales) participan de manera cada vez más activa en los sistemas de solución de las controversias en el ámbito internacional y así contribuyen al desarrollo y a la diversificación de los tribunales internacionales.

La función creciente que desempeñan los actores no estatales en los sistemas de resolución de las controversias internacionales propicia en diferentes maneras la "judicialización" del derecho internacional.

61 En la opinión de esta autora, el Estado ya no es “el capitán a bordo" del orden jurídico internacional. Además, cabe preguntarse si hay un “capitán” del todo (Delmas-Marty, Mireille, Ordering Pluralism. A Conceptual Framework for Understanding the Transnational Legal World, Hart publishing, 2009, pp. 149 y 150).

62 Otros autores utilizan el término de "pluralization" para referirse a la multiplicidad de actores y normas jurídicas internacionales (en particular, Klabbers, Jan et al., op. cit., p. 14).

63 Delmas-Marty, Mireille, op. cit., p. 102. 
En primer lugar, los actores no estatales son parte de los conflictos internacionales. En efecto, éstos desempeñan actividades cada vez más complejas en el ámbito internacional. En este sentido, los actores no estatales intervienen activamente en el comercio internacional, en las inversiones directas o indirectas que se realizan a nivel global, en las actividades relacionadas con el derecho internacional de la propiedad intelectual, etcétera. Estas actividades los sitúan en relaciones complejas con los Estados miembros de la comunidad internacional y en relaciones complejas entre sí. Dichas relaciones son fuente posible para el surgimiento de conflictos internacionales. A través de los conflictos de distinta índole que sus actividades internacionales generan, los actores no estatales crean una demanda para el establecimiento de jurisdicciones internacionales, competentes para resolverlos.

En segundo lugar, los actores no estatales pueden comparecer ante la gran mayoría de jurisdicciones internacionales con competencia regional. El locus standi de los litigantes privados (individuos y/o empresas trasnacionales) es uno de los temas más debatidos en la actualidad. Sin pretender a la exhaustividad, podemos citar varios ejemplos de la ampliación del locus standi de las personas privadas ante los tribunales internacionales.

Así, los litigantes no estatales pueden promover recursos ante elTJUE, ${ }^{64}$ ante el Tribunal de Justicia de la Comunidad Andina ${ }^{65}$ y ante el Tribunal de Justicia de la Comesa. ${ }^{66}$ Además, dichos litigantes tienen un acceso particularmente amplio al foro de las dos jurisdicciones regionales competentes en materia de derechos humanos. En efecto, la Convención Europea de Derechos Humanos ${ }^{67}$ reconoce la capacidad no solo de los particulares, sino también de las organizaciones no gubernamentales o de otros grupos de particulares de acudir ante la CEDH para que ésta sancione las violaciones de sus derechos humanos, en virtud de la Convención. La misma constatación es igualmente válida para el sistema interamericano de pro-

64 Según el artículo 173-4 del TCE, los individuos pueden presentar un recurso en anulación de un acto comunitario que les causa daños y perjuicios directos; también pueden participar en los recursos ante el Tribunal de la función pública y demandar la revisión de las multas que les son impuestas por un acto comunitario (en particular en derecho comunitario de la competencia).

65 Artículo 19 del Tratado del TJCA.

66 Artículo 26 del Tratado de Comesa.

67 Artículo 34 de la Convención Europea de Derechos Humanos. 
tección de los derechos humanos. En efecto, a pesar de que, en principio, los individuos no tienen acceso directo a la $\mathrm{CIDH},{ }^{68}$ las reformas recientes les han permitido participar de manera activa en sus procedimientos contenciosos. ${ }^{69}$

Siendo así, junto con los demás factores complejos, la creciente importancia de los actores no estatales en el ámbito de las relaciones internacionales propicia la "judicialización” del derecho internacional. Finalmente, existe otro factor complejo que intensifica dicho fenómeno. Este factor se relaciona con la pérdida de importancia del carácter consensual de la justicia internacional y la concepción de ésta como una "justicia obligatoria".

\section{La relativización del carácter consensual de la justicia internacional}

Tradicionalmente se consideraba que la justicia internacional era una justicia consentida (o consensual) y por lo tanto no obligatoria para los sujetos del derecho internacional. Como lo afirmó la CPJI en el caso Carelia del sur-este ${ }^{70}$ la resolución de controversias entre Estados soberanos se basa siempre y necesariamente en su consentimiento previo. En dicha sentencia, la Corte consideró que "ningún Estado puede, sin su consentimiento, ser llevado a someter sus disputas... a un arbitraje o cualquier otro método de solución pacífica de los diferendos". ${ }^{71}$

Mientras que la competencia de los tribunales internos es obligatoria, la de los tribunales internacionales es históricamente considerada como consensual. En el ámbito interno todos los jueces gozan de una jurisdicción

68 Los individuos no pueden presentar sus demandas directamente a la CIDH y deben someterlas a un examen preliminar por parte de la Comisión Interamericana de Derechos Humanos. En principio, solo la Comisión y los Estados miembros de la Convención interamericana de derechos humanos pueden presentar recursos directos ante la Corte.

69 El reglamento de la Corte fue modificado en 2001 y su artículo 37 dispone que: "Notificada la demanda a la presunta víctima o sus representantes debidamente acreditados, estos dispondrán de un plazo improrrogable de 2 meses, contado a partir de la recepción de este escrito y sus anexos, para presentar autónomamente a la Corte sus solicitudes, argumentos y pruebas".

70 CPJI, Opinión consultativa, Estatus de Carelia del este, 23 de julio de 1923, citada en Romano, Cesare, "The Shift from the Consensual to the Compulsory Paradigm in International Adjudication: Elements for a Theory of Consent”, International Law and Politics, vol. 39, 2007, p. 792.

71 Ibidem, párr. 19. 
obligatoria, lo que implica que una parte puede iniciar los procedimientos contenciosos unilateralmente y la otra es obligada a comparecer, sin necesidad de obtener su acuerdo previo. En el caso de la justicia internacional se trata de una jurisdicción consensual, en el sentido de que las partes en una controversia deben expresar su voluntad de participar en su resolución jurisdiccional. Este principio es un corolario del principio de soberanía e igualdad (soberana) entre los Estados. Por mucho tiempo este principio se consideraba como "la doctrina constitucional básica del derecho de las naciones, que regulaba una comunidad, compuesta principalmente de Estados que tienen una personalidad jurídica uniforme" (o igual). ${ }^{72}$ Por lo tanto, el consentimiento a ser "juzgado" internacionalmente se consideraba como una cesión de soberanía.

Como lo afirma Romano, durante todo el siglo XX el principio de consentimiento a la competencia de los tribunales internacionales siguió muy vigente y lo expresado por la CPJI en el asunto de Carelia del Este se convirtió en uno de los dogmas del derecho internacional. ${ }^{73}$ No obstante, como lo señala este autor, a partir de la década de los noventa y en la actualidad, el paradigma consensual ha perdido parte de su importancia. La "judicialización" del derecho internacional se ha acompañado y en parte ha sido provocada por el desarrollo de su contraparte: el principio de competencia obligatoria de los tribunales internacionales. Tanto en la teoría, como en la práctica del derecho internacional, la justicia internacional es cada vez más considerada como una justicia obligatoria y no consensada. El consentimiento a la justicia internacional no fue suprimido, pero su importancia para el funcionamiento de los tribunales internacionales es, en la actualidad, mucho menor. Su significado fue cambiando paulatinamente, convirtiéndolo en un "espectro muy pálido" de su expresión pasada. ${ }^{74}$

El funcionamiento de la mayoría de los tribunales internacionales ya no exige la expresión de un consentimiento previo a la iniciación de cada procedimiento contencioso. El consentimiento a la competencia de muchas jurisdicciones internacionales puede ser presumido o considerado como tácito porque resulta de la ratificación de sus estatutos constitutivos o de

72 Brownlie, Ian, Principles of International Law, 6a. ed., 2003, p. 287, cit. en Romano, Cesare, "The Shift from the Consensual to the Compulsory Paradigm in International Adjudication: Elements for a Theory of Consent", International Law and Politics, vol. 39, 2007, p. 793.

73 Idem.

74 Ibidem, p. 795. 
los tratados constitutivos de las organizaciones internacionales de las que dichas jurisdicciones forman parte. ${ }^{75}$ De la misma manera, en muchos casos, en la práctica judicial concreta de los tribunales internacionales, el consentimiento es relegado a un papel secundario y los procedimientos son de facto iniciados unilateralmente. ${ }^{76}$

75 Tal es el caso de la competencia de la CEDH y del sistema de resolución de las controversias de la OMC. En efecto, hasta 1994, el mecanismo de resolución de las controversias del antiguo GATT era basado en las negociaciones diplomáticas que necesariamente implicaban el consentimiento de sus Estados miembros. A partir de 1994, con la creación de la OMC, se estableció el nuevo mecanismo para la solución de las controversias en el ámbito de esta organización. El consentimiento a la competencia de los paneles de la OMC se deriva de la ratificación de sus acuerdos constitutivos. Dicho en otros términos, una vez que los Estados se vuelven miembros de la organización aceptan ipso facto la jurisdicción obligatoria de su mecanismo de solución de las controversias. La única posibilidad de oponerse a la constitución de un panel arbitral consiste en obtener un consenso negativo por parte de todos los miembros de la organización. Por lo tanto, en los hechos, la constitución de los paneles ya no es sujeta al consentimiento previo de los Estados miembros. La creación del órgano de apelación como segundo grado de jurisdicción reforzó aún más este carácter automático de la resolución de los litigios y “judicializó” el sistema de la OMC (Romano, Cesare, op. cit., p. 812). Podemos considerar que el consentimiento a la jurisdicción de los dos Tribunales penales internacionales ad hoc (elTPIY y elTPIR) también entra en esta categoría. En efecto, estas dos jurisdicciones fueron establecidas por el Consejo de Seguridad de la ONU (actuando sobre la base del Capítulo VII de la Carta de la ONU) para juzgar los crímenes internacionales cometidos en el territorio de la ex Yugoslavia y Ruanda. No obstante, el consentimiento expreso de ninguno de los dos Estados fue exigido para establecer la competencia obligatoria de las jurisdicciones. Dicho consentimiento podría presumirse del simple hecho que tanto la ex Yugoslavia como Ruanda son miembros de pleno derecho de la ONU (Romano, Cesare, op. cit., pp. 813 y 814). Finalmente, la misma consideración también es válida para la competencia de la CPI. En efecto de acuerdo al artículo 12-1 de su Estatuto constitutivo (Estatuto de Roma): "El Estado que pase a ser Parte en el presente Estatuto acepta por ello la competencia de la Corte...”.

76 Tal es el caso, por ejemplo, del establecimiento de la competencia de la CPI. La CPI fue establecida por un tratado internacional — el Estatuto de Roma- - Por lo tanto, de acuerdo al principio de pacta tertiis dicha jurisdicción sólo tendría jurisdicción obligatoria para los Estados que hayan ratificado su Estatuto. En este sentido, cabe señalar que muchos de los Estados siguen sin ratificar el Estatuto de Roma, precisamente con este objetivo (los dos ejemplos más significativos son tal vez los Estados Unidos e Israel). El Estatuto de Roma también establece la posibilidad de aceptar la competencia de la Corte por una declaración ad hoc y sin necesidad de ratificar su Estatuto. Además, en su práctica jurisprudencial concreta la Corte ha utilizado varios mecanismos para juzgar los nacionales de Estados que no han ratificado su Estatuto (y, por lo tanto, no han consentido a su competencia). En primer lugar, de acuerdo a lo establecido en el artículo 12-1 y 2 del Estatuto de Roma, la Corte puede ser competente para juzgar los individuos, nacionales de un Estado, que no haya aceptado la competencia de la Corte 
La concepción cada vez más compartida de la justicia internacional como una justicia obligatoria (y no consensual) contribuye al desarrollo e intensificación de la "judicialización" del orden jurídico internacional en varios aspectos. En primer lugar, la creciente posibilidad de iniciar los procedimientos internacionales contenciosos sin el acuerdo previo de los Estados y aún en contra de su voluntad, refuerza su eficacia. En segundo lugar, la relativización del paradigma consensual permite lograr una mayor legitimidad de las funciones contenciosas de los tribunales internacionales. La justicia internacional (obligatoria), así como el orden jurídico que ésta protege se objetivizan. En tercer lugar, la independencia de la competencia de los tribunales internacionales de un consentimiento estatal expreso se convierte en un importante estímulo para el desarrollo de su jurisprudencia. Cuanto más institucionalizada y automática se vuelve la resolución judicial de las controversias internacionales, tanto más se promoverá el recurso a sus mecanismos específicos.

\section{LOS RETOS DE LA “JUDICIALIZACIÓN” PARA EL FUNCIONAMIENTO DEL SISTEMA JURÍDICO INTERNACIONAL}

La "judicialización” del derecho internacional suscita dos principales retos para el funcionamiento del orden jurídico internacional. En primer lugar, este fenómeno se caracteriza por la creación de múltiples tribunales internacionales situados todos al mismo nivel. La multiplicación de jurisdicciones internacionales sin relaciones estructurales entre sí podría generar diversos tipos de conflictos en el ámbito internacional (1). En segundo lugar, la "judicialización” del derecho internacional conduce a una especialización creciente de los tribunales internacionales. La especialización de los tribu-

cuando sus actos son cometidos sobre el territorio o en contra de un nacional de un Estado parte del Estatuto de Roma. Finalmente, también existe la posibilidad de juzgar nacionales de un Estado que no haya consentido a la jurisdicción de la Corte cuando existe una demanda expresa en este sentido, presentada por el Consejo de Seguridad de la ONU, actuando sobre la base del Capítulo VII de la Carta de la ONU. Así, por una resolución del 31 de marzo de 2005 (Res. Núm. 1593), el Consejo de seguridad de la ONU refirió a la CPI varios crímenes internacionales cometidos por nacionales de Sudán en el territorio de Darfur, sin que Sudán haya consentido previamente a la jurisdicción de la Corte. 
nales internacionales se combina con la especialización de las normas que éstos deben aplicar e interpretar y provoca una serie de preocupaciones acerca del funcionamiento armonioso del orden jurídico internacional (1).

\section{La ausencia de vínculos formales entre los tribunales internacionales}

La multiplicación de los tribunales internacionales podría ser considerada como una evolución normal de todo orden jurídico. Dicha multiplicación responde a la necesidad de adaptar las instituciones jurídicas al desarrollo de las normas que éstas deben aplicar. No obstante, la multiplicación de los tribunales muchas veces implica la institución de reglas claras para la organización de sus relaciones interinstitucionales. En particular, se trata de definir las reglas aplicables a los posibles conflictos que los opondrían.

En los órdenes jurídicos internos los conflictos entre las distintas jurisdicciones nacionales son fáciles de resolver debido a que éstas mantienen entre sí relaciones de naturaleza vertical. ${ }^{77}$ No obstante, en el orden internacional no existe jerarquía entre los foros judiciales internacionales y sus relaciones son generalmente de carácter horizontal. ${ }^{78}$ Los distintos tribunales internacionales y las distintas normas jurídicas que éstos aplican e interpretan se sitúan al mismo nivel. Además, los tribunales internacionales no están sujetos a ninguna obligación de coordinación o cooperación en el desempeño de sus funciones judiciales.

En efecto, a diferencia de los sistemas nacionales de impartición de justicia, en el derecho internacional no existen un sistema judicial preestablecido ni una obligación para los Estados miembros de someter sus diferencias a jurisdicciones internacionales predeterminadas. ${ }^{79}$ Esta completa

77 En el ámbito nacional, los sistemas de impartición de justicia se caracterizan por la existencia de reglas de repartición vertical de las competencias entre las distintas jurisdicciones. Dicho en otros términos, existe una estricta jerarquía entre los distintos Tribunales nacionales. Así por ejemplo, la Corte Suprema de Justicia de los Estados Unidos es superior a los tribunales de distrito o circuito. De la misma manera, en México, la Suprema Corte de Justicia de la Nación ocupa un grado jerárquico superior en relación con los tribunales de distrito o circuito.

78 Graewert, Tim, "Conflicting Laws and Jurisdiction in the Dispute Settlement Process of Regional Trade Agreements and the WTO”, Contemporary Asia Arbitration Journal, vol. 1, núm. 2, 2008, p. 290.

79 Oellers-Frahm, Karin, "Multiplication of International Courts and Tribunals and Con- 
autonomía e independencia de los tribunales internacionales favorece el surgimiento de conflictos de competencia y conflictos de jurisprudencia en el ámbito internacional.

Los conflictos de competencia surgen cuando dos o más jurisdicciones internacionales son igualmente competentes para resolver la totalidad o parte de un litigio internacional. Muchas veces las mismas partes pueden ser tentadas de acudir, para la misma causa, ante dos foros internacionales distintos. Esta hipótesis de conflictos se agudiza cada vez más, visto que los tratados que instituyen jurisdicciones internacionales frecuentemente tratan de materias similares o idénticas. Además, el contenido de las normas que los tribunales internacionales aplican e interpretan se vuelve cada vez más heteróclito. Así por ejemplo, las normas relativas al comercio internacional muchas veces contienen aspectos de derecho del medio-ambiente, de derecho internacional de la competencia o de derecho marítimo internacional. De la misma manera, las normas relativas a la protección de los derechos humanos pueden incluir aspectos de derecho internacional humanitario o de derecho penal internacional, etcétera.

En la actualidad, hay muchos ejemplos de conflictos de competencia que se presentaron en la resolución concreta de los litigios internacionales. Así, en el caso del "Pez Espada", ${ }^{80}$ la controversia que oponía Chile a la $\mathrm{UE}^{81}$ fue sometida a la vez al TIDM ${ }^{82}$ y al sistema de arreglo de las diferencias de la OMC.$^{83}$ Otro ejemplo de conflicto de competencia entre los distintos tribunales internacionales concierne al sistema de solución de controversias

flicting Jurisdiction- Problems and Possible Solutions", Max Planck Institute for International and Comparative Law, UNYB, vol. 5, 2001, p. 74.

80 Stoll, Peter-Tobias y Silja Vdneky “The Swordfish Case: Law of the Sea v. Trade”, Max Planck Institue foir International and Comparative Law, UNYB, 2000.

81 La controversia se originaba en la prohibición, por parte de Chile, del acceso de barcos provenientes de Estados miembros de la UE en los puertos chilenos. Dicha prohibición tenía como objetivo evitar la importación de pez espada en el territorio de este país. Según la Comisión europea, la prohibición chilena violaba no solo la Convención de las NU sobre el Derecho del Mar sino también varias disposiciones del GATT de 1994. Cabe señalar que los países llegaron a un arreglo extra-judicial de la controversia y los dos procedimientos contenciosos fueron suspendidos.

82 ITLOS, Case 7: Case concerning the Conservation and Sustainable Exploitation of Swordfish Stocks in the South-Eastern Pacific Ocean (Chile/European Union), order 2/2003 of 20 December 2000 .

83 OMC, Chile - Measures Affecting the Transit and Importation of Swordfish, Request for the Establishment of a Panel by the European Communities, 7 de noviembre de 2000. 
de la $\mathrm{OMC}$ y los sistemas de arreglo de diferencias previstos en los acuerdos regionales de libre comercio, concluidos por sus Estados miembros. ${ }^{84}$ En efecto, casi todos los Tratados de Libre Comercio (TLC) prevén una cláusula específica, relativa a la resolución de las controversias que surgen de la interpretación o aplicación de sus disposiciones. Muchas veces, tanto los tribunales establecidos por los TLC, como el mecanismo de arreglo de controversias de la OMC, son competentes para resolver los litigios que oponen a sus miembros. Podemos pensar en la larga controversia de la "madera blanda" que opuso los Estados Unidos a Canadá. Dicha diferencia fue sometida a la vez a los paneles delTLCAN y a los de la OMC. ${ }^{85}$ Finalmente, cabe señalar que los conflictos de competencia pueden involucrar no solo dos, sino también tres o más jurisdicciones internacionales. ${ }^{86}$ Así por ejemplo, la CIJ tuvo que pronunciarse sobre una alegación por parte de Bosnia y Herzegovina respecto a la comisión, en su territorio, de crímenes de genocidio por parte de Serbia y Montenegro en los años $1990 .{ }^{87} \mathrm{Al}$ mismo tiempo, el TPIY examinó la responsabilidad de Slobodan Milosevic ${ }^{88}$ y de

84 En la actualidad, casi todos los Estados miembros de la OMC han concluido un gran número de tratados bi o multilaterales de libre comercio que coexisten con su sistema de liberalización comercial. Podemos pensar en las distintas integraciones regionales de Estados (Mercosur, TLCAN, UE, MCCM, Caricom, CAN, Comesa, etcétera) pero también en los tratados de libre comercio entre los distintos Estados miembros de la OMC (TLC Estados Unidos-Nicaragua, TLC México-Israel, etcétera).

85 OMC, United States-Investigation of the International Trade Commision in Softwood Lumber from Canada, Recourse by Article 25.1 of the DSU by Canada-Report by Panel, 9 de Mayo de 2006; Re Matter of Certain Softwood Lumber Products from Canada (opinion and Order), NAFTA, Extraordinary Challenge Committee, 10 de agosto de 2005. En 2005, las dos jurisdicciones adoptaron fallos contradictorios sobre el mismo asunto. El mismo tipo de conflicto de competencia ocurrió en 2005 en el caso Mexico-Soft Drinks que fue sometido a la vez a un panel delTLCAN y al mecanismo de solución de las controversias de la OMC.

86 Así por ejemplo, en el caso "MOX Plant" (Irlanda c/ Reino Unido) intervinieron tres distintos Tribunales internacionales. En primer lugar, Irlanda solicitó la constitución de un Tribunal arbitral bajo la Convención de las Naciones Unidas sobre el Derecho del mar (Anexo VII). Al mismo tiempo fue constituido otro Tribunal arbitral ad hoc bajo la Convención para la protección del medio-ambiente marino del noreste del Atlántico (Convención OSPAR). Finalmente, el TJUE resolvió el asunto en mayo de 2006, estimando que se trataba de un litigio de Derecho comunitario.

87 CIJ, Case concerning the Application of the Convention on the Prevention and Punishment of the Crime of Genocide, Bosnia and Herzegovina vs. Serbia and Montenegro, 26 de febrero de 2007, http: / / www.icj-cij.org/docket/files/91/13685.pdf.

88 El caso fue cerrado después de la muerte del Milosevic en la cárcel. 
Radovan Karadzic, ${ }^{89}$ en particular, por la comisión de actos de genocidio en este mismo territorio. Por su parte, el TPIR se ha pronunciado sobre varios casos relativos a actos de genocidio, cometidos en el territorio de Ruanda. Paralelamente, varias demandas interestatales sobre los mismos hechos fueron llevadas ante la CIJ, pero no pudieron reunir las condiciones de admisibilidad. ${ }^{90}$

Por su parte, los conflictos de jurisprudencia ocurren cuando una o más jurisdicciones internacionales llegan a conclusiones opuestas sobre un caso similar o idéntico. Dichos conflictos son considerablemente acentuados por la "judicialización” del orden jurídico internacional. La multiplicación de los tribunales internacionales ha vuelto el arreglo judicial de los litigios internacionales casi rutinario. Por lo tanto, cada vez más jurisdicciones internacionales son llevadas a pronunciarse sobre problemas jurídicos que fueron objeto de controversias, previamente resueltas por otros tribunales internacionales. ${ }^{91}$ Como lo señaló la CIDH en su Opinión consultativa sobre el derecho de información sobre la asistencia consular:

En todo sistema jurídico es un fenómeno normal que distintos tribunales que no tienen entre sí una relación jerárquica puedan entrar a conocer y, en consecuencia, a interpretar, el mismo cuerpo normativo, por lo cual no debe extrañar que, en ciertas ocasiones, resulten conclusiones contradictorias o, por lo menos, diferentes sobre la misma regla de derecho. ${ }^{92}$

En la actualidad existen varios ejemplos concretos de conflictos de jurisprudencia entre los distintos tribunales internacionales. Así por ejemplo, en el caso "Tadic"93 el TPIY sostuvo consideraciones contrarias a las ex-

89 TPIY, Prosecutor vs. Radovan Karadzic, indictment "Srebrenica”, 24 de noviembre de 1995; indictment "Bosnia and Herzegovina", 24 de julio de 1995, http://www.icty.org/case/kara dzic/4.

$90 \mathrm{CIJ}$, Armed Activities on the Territory of the Congo, Democratic Republic of the Congo v Rwanda, 3 de febrero de 2006, http://www.icj-cij.org/docket/files/126/10435.pdf.

91 Kingsbury, Benedict, "Foreword: is the proliferation of International Courts and Tribunals a Systemic Problem”, International Law and Politics, vol. 31, 2003, p. 684.

92 CIDH, Opinión consultiva OC-16/99, "El derecho a la información sobre la asistencia consular en el marco de las garantías del debido proceso legal”, 1 de octubre de 1999, http: / / www.cidh.org/migrantes / Opini\%C3\%B3n\%20Consultiva\%2016.htm, párr. 61.

93 TPIY, Prosecutor v. Tadic, 7 de mayo de 1997; decisión de la Cámara de apelaciones, 15 de julio de 1999. 
presadas por la $\mathrm{CIJ}$ en el asunto Actividades militares y paramilitares en Nicaragua. ${ }^{94}$ Las dos jurisdicciones internacionales llegaron a conclusiones contradictorias respecto al mismo concepto de "conflicto (armado) internacional". ${ }^{95}$ Otro ejemplo de conflictos de jurisprudencia puede ser identificado en varias sentencias de la CEDH y del TJUE. ${ }^{96}$ En varias decisiones, el TJUE interpretó las disposiciones de la Convención Europea de Derechos Humanos de manera mucho más restrictiva que la CEDH y las jurisprudencias de ambas jurisdicciones contenían aspectos claramente contrarios. ${ }^{97}$ Otros casos de conflictos de jurisprudencia resultan de las sentencias de los tribunales arbitrales del CIADI. ${ }^{98}$ Frecuentemente puede ocurrir que dos o más tribunales arbitrales ad hoc lleguen a conclusiones completamente opuestas sobre litigios similares o idénticos. ${ }^{99}$ En el mismo sentido, en varias sentencias, la CEDH y el TJUE ${ }^{100}$ interpretaron y aplicaron la Convención Europea de Derechos Humanos de manera clara-

94 CIJ, Actividades militares y paramilitares en Nicaragua, 27 de junio de 1986, http: / / www.icj-cij.org/docket $/$ index.php?sum $=367 \&$ code $=$ nus\&p1 $=3 \& p 2=3 \&$ case $=70 \& k=66 \& p 3=5$.

95 En el caso Tadic la Cámara de apelaciones del TPIY tuvo que determinar si el conflicto armado que opuso los serbios bosniacos a las autoridades centrales de Bosnia y Herzegovina podía ser calificado como "conflicto internacional". La Cámara de apelaciones se refirió a la solución adoptada por la CIJ en el caso Actividades militares y paramilitares en Nicaragua. No obstante, en su sentencia, la Cámara de apelaciones criticó la determinación de la noción de “control” por parte de la CIJ y modificó considerablemente sus alcances.

96 Reinisch, August, "The Use and Limits of Res Judicata and Lis Pendens as Procedural Tools to Avoid Conflicting Dispute Settlement Outcomes”, Law and Practice of International Courts and Tribunals, vol. 3, 2004, p. 39.

97 En particular en la sentencia Hoechst $A G$ c/ Comisión (casos 46/87 y 227/88, 1989), el TJUE estimó que el derecho a la privacidad protegido por el artículo 8 de la Convención Europea de Derechos Humanos no podía ser extendido a las actividades de negocios. Esta interpretación fue completamente rechazada por la CEDH. En el caso Niemietz c/ Alemania (6 de diciembre de 1992) la CEDH estimó que la noción de "vida privada" contenida en el artículo 8o. de la Convención Europea de Derechos Humanos incluía las actividades profesionales y de negocios.

98 Reinisch, August, op. cit., párrafo 7.

99 Así por ejemplo en los casos SGS Société Générale de Surveillance SA v Islamic Republic of Pakistan (Objections to Jurisdiction; CIADI, caso núm. ARB/01/13) y SGS Société Générale de Surveillance SA v Philippinnes (Objection to Jurisdiction; CIADI, 2005) dos tribunales arbitrales del CIADI llegaron a conclusiones contrarias respecto a la interpretación de unas cláusulas muy similares contenidas en los tratados bilaterales de inversión aplicables al caso.

100 Reinisch, August, op. cit., p. 39. 
mente contradictoria. ${ }^{101}$ De igual manera, en 1999, en su Opinión consultativa sobre el derecho a la información sobre la asistencia consular, ${ }^{102}$ la CIDH consideró que el derecho individual previsto en el artículo 36-1 b) de la Convención de Viena sobre Relaciones Consulares formaba parte del “cuerpo del derecho internacional de los derechos humanos". ${ }^{103}$ En 2001, la CIJ, en el caso Lagrand señaló que no era necesario pronunciarse sobre el carácter de "derecho humano" de lo previsto en dicho artículo. ${ }^{104}$ Unos años después, México se lo volvió a preguntar en el caso Avena ${ }^{105}$ y la CIJ afirmó que la consideración del derecho individual previsto en el artículo 36 como un derecho humano no puede deducirse ni del texto del artículo ni de sus travaux préparatoires. ${ }^{106}$

Tanto los conflictos de competencia como los conflictos de jurisprudencia entre los tribunales internacionales son susceptibles de perjudicar la operación eficaz del orden jurídico internacional.

Los conflictos de competencia se originan en la falta de coordinación de los aspectos procesales del funcionamiento de los tribunales internacionales. La existencia de múltiples procedimientos sucesivos o paralelos sobre la misma causa podría provocar varios problemas para la pronta y eficaz resolución de las controversias internacionales. La resolución de dichos problemas necesita la adopción de reglas alternativas para la articulación de las competencias de las jurisdicciones internacionales. ${ }^{107} \mathrm{~A}$ diferencia de los conflictos de competencia, los conflictos de jurisprudencia entre los múltiples tribunales internacionales no conciernen la articulación procesal entre dichas jurisdicciones sino la manera de interpretar y aplicar las normas

101 En particular en la sentencia Hoechst $A G$ c/ Comisión (casos 46/87 y 227/88, 1989), el TJUE estimó que el derecho a la privacidad protegido por el artículo 8 de la Convención europea de derechos humanos no podía ser extendido a las actividades de negocios. Esta interpretación fue completamente rechazada por la CEDH. En el caso Niemietz c/ Alemania (6 de diciembre de 1992) la CEDH estimó que la noción de "vida privada" contenida en el artículo 8 de la Convención europea de derechos humanos incluía las actividades profesionales y de negocios.

102 CIDH, Opinión consultiva OC-16/99, cit.

103 CIDH, Opinión consultiva OC-16/99, cit., párr. 141.

104 CIJ, Lagrand, Alemania v. Estados Unidos, 27 de junio de 2001, http: / / www.icj-cij.org/ docket/files/104/7736.pdf, párr. 77-78.

105 CIJ, Avena y otros nacionales mexicanos, México v. Estados Unidos, 31 de marzo de 2004, http: / / www.icj-cij.org/docket/files/128/8188.pdf.

106 Caso Avena, cit., párr. 30.

107 Shany, Yyuval, op. cit., p. 22. 
internacionales. Los conflictos de jurisprudencia son de carácter sustancial y se refieren a la solución jurídica del fondo de un litigio. Estos conflictos entre las sentencias internacionales son una consecuencia muy negativa de la “judicialización” del derecho internacional.

Las interpretaciones y aplicaciones contradictorias de las normas internacionales podrían conducir a la imposición de obligaciones contradictorias y/o contrarias a los Estados miembros de la comunidad internacional. Por ejemplo, la interpretación y la aplicación judicial de una misma norma o de un mismo principio impondrían obligaciones divergentes a un mismo Estado, dependiendo del tribunal internacional al que éste acuda. Así, un Estado podría ser sancionado por una violación del principio de buena fe por parte de una sentencia del ORD de la OMC. El mismo Estado (u otro Estado en una situación jurídica similar o idéntica) podría acudir a otro tribunal internacional y, mediante una interpretación y aplicación distinta del principio de buena fe, este juez podría considerar que el Estado no cometió una violación a dicho principio.

La variación en la aplicación e interpretación del derecho internacional por parte de los múltiples tribunales internacionales provocaría una multitud de problemas fácticos para el control judicial de los compromisos internacionales y para el balance entre los derechos y obligaciones que se derivan de las normas y principios internacionales. En particular, los litigantes en el ámbito internacional perderían la posibilidad de prever las consecuencias jurídicas de sus actos y se expondrían a múltiples controles judiciales, basados en distintas concepciones jurisprudenciales del derecho internacional. Además, si los tribunales internacionales aplican e interpretan las normas internacionales de manera divergente, se pondría en tela de juicio su propia legitimidad. Los actores de la comunidad internacional (estatales o no estatales) perderían su confianza en los jueces internacionales y en la credibilidad de su jurisprudencia. Esta situación sería sin duda perjudicial para la operación coherente y eficaz del derecho internacional.

La falta de coordinación en la actividad jurisprudencial de los distintos tribunales internacionales es terreno fértil para el desarrollo de otro fenómeno estrechamente relacionado con la "judicialización” del derecho internacional. En efecto, la multiplicación de los tribunales internacionales incrementa la posibilidad para sus justiciables de librarse al fórum shopping.

El fórum shopping consiste en la posibilidad que tienen los litigantes de escoger entre los distintos mecanismos que pueden resolver su controversia, el 
que estimen más favorable para la defensa de su causa. ${ }^{108}$ El fórum shopping es un fenómeno reciente en el derecho internacional. Mientras que en los años anteriores a $1989,{ }^{109}$ los litigantes podían escoger entre dos o tres tribunales competentes para resolver su controversia, en la actualidad pueden acudir a más de veinte. Este incremento de los foros disponibles para la resolución de las controversias internacionales es sin duda benéfico para los litigantes en el derecho internacional. ${ }^{110}$ La existencia de múltiples foros permite obtener la resolución satisfactoria de las controversias "multifacéticas". ${ }^{111}$ El fórum shopping también es susceptible de promover la existencia de un cierto grado de competencia "sana" entre las distintas jurisdicciones internacionales. ${ }^{12}$ Dicha competencia podría promover la eficacia y mejorar el funcionamiento concreto de los distintos tribunales internacionales. A pesar de sus beneficios, el fórum shopping representa una serie de peligros importantes para la solución de las controversias en el derecho internacional. Dicho fenómeno propicia el surgimiento de nuevos conflictos de competencia y de jurisprudencia entre las distintas jurisdicciones internacionales. Además, el fórum shopping puede conducir a la obstrucción de algunas jurisdicciones internacionales que los justiciables consideren más favorables para la resolución de sus conflictos. De la misma manera, el fórum shopping puede afectar la

108 Cabe señalar que el fórum shopping es generalmente considerado como un concepto de derecho internacional privado y se utiliza para determinar los motivos por los que una persona decide presentar su litigio a un determinado tribunal, nacional o internacional. Dichas motivos pueden depender de múltiples factores, como por ejemplo del derecho aplicable al caso. Un litigante puede escoger un foro judicial específico porque las reglas jurídicas que éste aplica le son más favorables.

109 Así, en 1986, Sir Gerald Fitzmaurice afirmaba que en el derecho internacional es muy raro encontrar más que un (sólo) Tribunal competente para resolver una controversia determinada (Fitzmaurice, Gerald, The Law and Procedure of the International Court of Justice, Merrils, 1986, p. 437, cit. en Pauwelyn, Joost y Salles, Luiz Eduardo, "Forum shopping Before International Tribunals: (Real) Concerns, (Im)Possible Solutions”, Cornell International Law Journal, vol. 42, 2009, p. 80).

110 Idem.

111 Como por ejemplo, las que presentan aspectos de derecho comercial internacional (ante el mecanismo de solución de las controversias de la OMC) y de derecho internacional del mar (ante el TIDM) o las que se refieren a problemas de delimitación territorial (ante la CIJ) y a problemas de restricciones al comercio (ante el mecanismo de arreglo de diferencias del Mercosur).

112 Pauwelyn, Joost, op. cit., p. 80. 
prontitud de la impartición de la justicia por parte de los tribunales internacionales y dejar varios asuntos importantes irresueltos. ${ }^{113}$

\section{La especialización de los tribunales internacionales}

y su relación con la "compartimentación" del derecho internacional

El segundo reto de la “judicialización” para el funcionamiento del orden jurídico internacional se relaciona con la especialización de los tribunales internacionales descentralizados. En efecto, la "judicialización” se desarrolla en un contexto, marcado por la "compartimentación” del derecho internacional. Esta "compartimentación" resulta de la especialización creciente de las normas internacionales y se refiere a la aparición de múltiples "disciplinas jurídicas" en el ámbito internacional. Hace apenas algunas décadas el "label" de "derecho internacional" era utilizado para nombrar al derecho internacional público o al derecho internacional privado. Esto ha cambiado radicalmente en la actualidad porque asistimos al desarrollo de muchos otros "derechos internacionales": el derecho internacional de los derechos humanos, el derecho internacional del mar, el derecho penal internacional, el derecho del comercio internacional, el derecho internacional de las inversiones, el derecho internacional monetario y financiero, el derecho internacional de la competencia, el derecho internacional humanitario, el derecho internacional del medio ambiente, el derecho internacional del espacio ultra-terrestre, el derecho internacional del trabajo, el derecho agrario internacional, para mencionar solo algunos.

En este sentido, la "compartimentación” del derecho internacional designa la tendencia a estudiar, enseñary sobre todo aplicar un derecho internacional particular (o especializado) en "aislamiento clínico" del resto de las disciplinas, y del derecho internacional general. ${ }^{114}$ Como lo señala Prost,

113 La disponibilidad de muchos mecanismos para la solución de las controversias podría llevar las partes en los litigios internacionales a desistir de su resolución ante un tribunal internacional para introducir una (nueva) demanda ante otra jurisdicción que consideren más favorable para la defensa de sus intereses particulares.

114 Prost, Mario y Fouret, Julien, "La multiplication des juridictions internationals: de la nécessité de remettre quelques pendules à l'heure, Revue québécoise de droit international, vol. 15.2, 2002, p. 132; Brownlie, Ian, Problems of specialization”, en Cheng, Bin, International Law: Teaching and Practice, Stevens and Sons, 1982, p. 45. 
se trata del peligro de "saucissonnage" (troceado) del derecho internacional a través de una lectura "autárquica" de sus distintas materias especializadas. ${ }^{115}$

Este fenómeno es particularmente visible en algunos ámbitos. Por ejemplo, la especialización y las características intrínsecas de las normas del derecho comunitario de la UE permitieron alTJUE erigirlo en un "nuevo orden jurídico de Derecho internacional". ${ }^{116}$ Como si la UE no fuera un "club" de Estados ${ }^{117}$ —una organización internacional, creada por tratados internacionales y compuesta por Estados soberanos-_. ${ }^{118}$ En el mismo sentido, la CEDH consideró que la Convención Europea de Derechos Humanos es más que "un tratado internacional clásico" porque no establece simplemente "compromisos recíprocos entre los Estados parte", sino "obligaciones objetivas" que se benefician de su "aplicación colectiva". ${ }^{119}$ En el mismo sentido, a pesar de la ausencia de normas jurídicas vinculantes en la materia, muchos autores se basan en los principios expresados en la Cumbre de la Tierra de Río para sostener la existencia de un "derecho internacional del desarrollo sustentable” que incluirá al derecho internacional del comercio sustentable (sustainable international trade law), derecho sustentable de los derechos humanos y de la erradicación de la pobreza (sustainable human rights law and poverty eradication), derecho internacional sustentable de los recursos naturales (sustainable international natural ressources law) o derecho internacional sustentable del cambio climático y de la vulnerabilidad (sustainable international climate change law and vulnerability). ${ }^{120}$

Esta "compartimentación" de las disciplinas podría tener un doble efecto negativo en relación con la "judicialización” del orden jurídico internacional. En primer lugar, dicha "compartimentación” podría hacer que la resolución judicial de las controversias internacionales se haga en un "hermetismo (o vacuum) normativo”. En segundo lugar, la “compartimentación”

115 Prost, Mario y Fouret, Julien, op. cit., p. 132.

116 TJUE, Van Gend en Loos, 5 de febrero de 1963.

117 Carreau, Dominique, Droit international public, ed. Pédone, 2003.

118 Pellet, Allain, "Les fondements juridiques internationaux du droit communautaire", Recueil de cours de l'Académie de droit européen, vol. 5, 1994, p. 211.

119 CEDH, Ireland v. UK, 1 de enero de 1978, http://hudoc.echr.coe.int/sites/eng/pages/ search.aspx?i=001-57506\#\{“itemid”:[“001-57506”]\}, párr. 239.

120 En este sentido, consultar los programas de investigación del Centro para el Derecho internacional del desarrollo sustentable, www.cisdl.org/programmes.html, citado en Prost, Mario y Julien Fouret, op. cit., p. 121. 
de las disciplinas internacionales podría conducir a una “idiosincrasia” en la interpretación y aplicación del derecho internacional.

Todos los tribunales internacionales especializados fueron establecidos para aplicar un conjunto de normas internacionales específicas: los tribunales, competentes en materia de derechos humanos aplican el derecho internacional de los derechos humanos, los tribunales penales internacionales aplican el derecho penal internacional, el mecanismo de solución de controversias de la OMC aplica el derecho de la OMC, el TIDM aplica el derecho internacional del mar, etcétera.

En primer lugar, en virtud de un "hermetismo normativo", estos tribunales internacionales especializados podrían optar por la aplicación exclusiva de las normas especializadas que justificaron su creación. Así por ejemplo, los tribunales internacionales competentes en materia de derechos humanos aplicarían únicamente el derecho internacional de los derechos humanos y el mecanismo de solución de las controversias de la OMC aplicaría únicamente el derecho del comercio internacional.

Este peligro está lejos de ser una exageración teórica. Basta con leer la sentencia del OA de la OMC en el caso Hormonas ${ }^{121}$ para darse cuenta de su realidad. En dicho asunto, el OA tuvo que pronunciarse sobre la naturaleza jurídica del principio de cautela y consideró que: "Algunos consideran que el principio de cautela se ha cristalizado en un principio general del derecho medioambiental internacional consuetudinario...” y que su naturaleza de "principio de derecho internacional general o consuetudinario parece menos clara”. ${ }^{122}$ Finalmente, el Órgano de Apelación afirmó que “... el principio de cautela, por lo menos fuera del ámbito del derecho medioambiental internacional, aún no tiene una formulación autorizada”. ${ }^{123}$ De esta manera, el OA excluyó la aplicación del principio de cautela en el ámbito del derecho de la OMC. Sin ningún matiz, el OA consideró que, aún si el principio de cautela constituye un principio del derecho medioambiental internacional consuetudinario, dicho principio no es obligatorio en el ámbito del derecho de la OMC. La "división” entre el derecho de la OMC y el derecho internacional medioambiental parece subrayar la posibilidad para

121 OMC, CE-Medidas que afectan la carne y los productos cárnicos (Hormonas), 16 de enero de 1998, http: / /www.wto.org/spanish/tratop_s/dispu_s/cases_s/ds48_s.htm.

122 Caso Hormonas, cit., núm. 123.

123 Idem. 
el "juez" de la OMC de funcionar eficazmente en un "hermetismo normativo", aplicando únicamente las normas especializadas que justificaron su creación.

En segundo lugar, la "compartimentación" de las normas internacionales podría afectar su aplicación e interpretación por parte de los múltiples tribunales internacionales. El mandato de los tribunales internacionales especializados consiste en aplicar las normas internacionales especializadas de acuerdo a su objeto y fin particular. ${ }^{124} \mathrm{La}$ "idiosincrasia" ${ }^{25} \mathrm{o}$ "sensibilidad" distinta de los objetivos y fines, propios a un conjunto de normas internacionales especializadas, es susceptible de influenciar la manera en la que los tribunales internacionales aplican no solo dicho conjunto especializado, sino también el resto de las normas internacionales. Cada tribunal internacional estaría comprometido en una lucha hegemónica destinada a presentar el interés particular de las normas especializadas que justificaron su creación como el interés general. ${ }^{126}$ Estaríamos entonces en un escenario de "guerra de los derechos" ${ }^{127}$ internacionales. Dicha guerra afectaría la legibilidad del derecho internacional: es decir, la adopción de una visión conjunta del mismo. ${ }^{128}$

Así por ejemplo, no es de extrañarse que la CIDH — jurisdicción internacional, competente para la promoción de los fines y objetivos específicos del derecho internacional de los derechos humanos - consideró que el derecho previsto en el artículo 36 de la Convención de Viena sobre Relaciones Consulares constituía un derecho humano, ${ }^{129}$ mientras que la CIJ, a través de otra interpretación y aplicación "idiosincrásica" de la misma norma internacional, se negó rotundamente a incluir lo establecido en dicho artículo en la categoría de derechos humanos. ${ }^{130}$

124 CDI, Reporte del grupo de trabajo sobre la fragmentación del derecho internacional, párr. 11-16.

125 Shany, Yuval, op. cit., pp. 29 y 30.

126 Koskenniemi, Martti y Leino, Paivi, "Fragmentation of International Law: Post-Modern Anxieties”, Leiden Journal of International Law, vol. 15, 2005, p. 562.

127 Denys Simon, Afirmación sostenida en el debate sobre "Les juridictions régionales: renforcement ou émiettement du droit international?", Colloque du centre d'études sur le droit international et la mondialisation, "Les juridictions internationales : complémentarité ou concurrence?", Montréal, 26 mai 2003, cit. en Prost, Mario y Julien Fouret, op. cit., p. 125.

128 Prost, Mario y Fouret, Julien, op. cit, p. 131.

129 CIDH, Opinión consultiva OC-16/99, cit.

130 Op. cit., pp. 105 y 106. 
Tanto el "hermetismo", como la "idiosincrasia" en la aplicación e interpretación del derecho internacional son perjudiciales para el funcionamiento eficaz del orden jurídico internacional. El "hermetismo normativo" podría afectar la eficacia en la resolución de las controversias internacionales. Los "derechos internacionales" especializados no son susceptibles de dar respuesta a la totalidad de situaciones fácticas que surgen en los litigios internacionales. La presencia de lagunas o contradicciones en estos conjuntos normativos enfrentaría a los tribunales internacionales que los aplican a problemas jurídicos complejos. Por su parte, la "idiosincrasia" en la aplicación e interpretación del derecho internacional podría afectar su coherencia. El riesgo de interpretaciones y aplicaciones divergentes de las normas y principios del derecho internacional es perjudicial para la previsibilidad del sistema jurídico internacional.

Además, tanto el "hermetismo normativo", como la "idiosincrasia" en la interpretación y aplicación del derecho internacional podrían conducir al surgimiento de subsistemas o regímenes autónomos en el ámbito del derecho internacional. Dichos regímenes perjudicarían la sistematicidad del orden jurídico internacional. En esta hipótesis, no existiría un solo orden jurídico internacional, sino varios sistemas jurídicos que se autorregularán a la escala global. ${ }^{131}$ Como lo señala Abi-Saab, esta "miríada”"132 de sistemas o subsistemas se asemejarían a un (monstruo de) "Frankestein jurídico" porque no compartirían las mismas bases de legitimidad y criterios formales de pertenencia. ${ }^{133}$ La "compartimentación" desvincularía tanto las normas internacionales, como los tribunales que operan en el ámbito internacional. Estaríamos en presencia de varios "feudos" ${ }^{134}$ normativos y judiciales, sin nada en común.

131 Teubner, Gunther, Law as an Autopoeitic System, The European University Institute Press Series, 1993; Teubner, Gunther, Global Law Without a State, Dartmouth, 1997.

132 Cassese, Antonio, "Remarks on Scelle's Theory of 'Role Splitting' (dédoublement fonctionnel) in International Law”, European Journal of International Law, vol. 2, 1990, p. 210.

133 Abi-Saab, "Fragmentation or Unification: Some Concluding Remarks", New York Journal of International Law and Politics, vol. 31, 1999, pp. 919-926.

134 Dupuy, Pierre-Marie, "L'unité de l'ordre juridique international", Recueil de cours de l'Académie de droit international de la Haye, t. 297, 2002. 


\section{CONCLUSIÓN}

En la actualidad, la “judicialización” del sistema jurídico internacional es una de sus características más interesantes. La multiplicación de los tribunales internacionales permite consolidar el arreglo judicial de las diferencias y promover así su resolución pacífica. La multiplicación de los órganos judiciales internacionales aumenta la eficacia de las normas internacionales y la correcta ejecución de los derechos y/u obligaciones que éstas generan para sus destinatarios. El control legal e imparcial que estos órganos ejercen sobre el respeto de las normas internacionales “objetiviza" el derecho internacional. Al resolver las controversias que les son sometidas, las jurisdicciones internacionales no solo aplican e interpretan el derecho internacional. Los tribunales internacionales desarrollan las normas y los principios que deben guiar la resolución del fondo de los litigios. Cuantas más jurisdicciones deciden casos basados en el derecho internacional, tanto más las normas pertenecientes a este último podrán ser aclaradas y consolidadas. Finalmente, la multiplicación de los foros que aplican el derecho internacional es susceptible de mejorar su entendimiento por parte de los integrantes de la comunidad internacional. Cada vez que los miembros de la sociedad internacional someten la resolución de sus litigios a un órgano jurisdiccional, este último, al "decir el derecho", lo vuelve mucho más claro y comprensible.

A pesar de sus múltiples ventajas, la "judicialización” provoca algunos riesgos para el funcionamiento eficaz del orden jurídico internacional. Los conflictos de competencia y jurisprudencia entre los distintos tribunales internacionales, el forum shopping o el peligro de "compartimentación" excesiva del derecho internacional por parte de los tribunales especializados que operan en su ámbito, son problemas reales que se derivan de la "judicialización” del sistema jurídico internacional. Pero la gravedad de estos problemas no conduce al orden jurídico internacional hacia un escenario apocalíptico. Los retos de la "judicialización” no son irremediables.

Es posible hallar dos soluciones alternativas a los problemas suscitados por la falta de relaciones formales entre los distintos tribunales internacionales. La primera solución consistiría en establecer una coordinación vertical o jerárquica entre las distintas jurisdicciones internacionales y, la segunda, en promover una coordinación horizontal e informal, basada en la complementariedad de las mismas. 
De la misma manera, los problemas suscitados por la especialización de los múltiples tribunales internacionales podrían ser resueltos, en parte, por el recurso a principios normativos comunes que fungirían como “... un potente "cimiento" que une las distintas y muchas veces disparejas piezas y ruedas del marco normativo de la Comunidad internacional”. ${ }^{135}$

\section{BIBLIOGRAFÍA}

ABI-SAAB, Georges Michel, "The Normalization of International Adjudication: Convergence and Divergence", International Law and Politics, vol. 43, 2010.

-, The International Judicial Function, UN Lecture Series, http://un treaty.un.org/cod/avl/ls/Abi-Saab_CT_video_1.html.

— , "Fragmentation or Unification: Some Concluding Remarks", New York Journal of International Law and Politics, vol. 31, 1999.

ALFORD, Roger, "The Proliferation of International Courts and Tribunals: International Adjudication in Ascendance", American Journal of International Law, vol. 94, 2000.

BODACK, Jessica, "International Law for the Masses", Duke Journal of Comparative and International law, vol. 15.

Brownlie, Ian, Principles of International Law, 6a. ed., 2003. , "Problems of Specialization", En Cheng, Bin, International Law: Teaching and Practice, ed. Stevens and Sons, 1982.

BURKe-White, William, "International Legal Pluralism”, Michigan Journal of International Law, vol. 25, 2004.

Cançado Trindade, Antonio Augusto, La expansión de la jurisdicción internacional y su realización de la justicia, UN Lecture Series, http://legal. un.org/avl/1s/Cancado-Trindade_HR_video_2.

CAssese, Sabino, “Remarks on Scelle's Theory of 'Role Splitting' (dédoublement fonctionnel) in International Law”, European Journal of International Law, vol. 2, 1990.

, International Law, Oxford University Press, 2005.

135 Cassese, Sabino, International Law, Oxford University Press 2005, p. 188. 
Delmas-Marty, Mireille, Ordering Pluralism. A Conceptual Framework for Understanding the Transnational LegalWorld, ed. Hart publishing, 2009.

DuPUY, Pierre-Marie, “The Danger of Fragmentation or Unification of the International Legal System and the International Court of Justice", International Law and Politics, 1999.

, “L'unité de l'ordre juridique international”, Recueil de Cours de l'Académie de Droit International de la Haye, t. 297, 2002.

FitzMaurice, Gerald, The Law and Procedure of the International Court of Justice, Merrils.

FRIEDmann, Wolfgang, The Changing Structure of International Law, Columbia University Press, 1964.

FRISON-ROCHE, Marie-Anne, "Droit international économique et mondialisation", Les grandes questions du droit économique, París, Quadrige-PUF, 2005.

GraEWERT, Tim, "Conflicting Laws and Jurisdiction in the Dispute Settlement Process of Regional Trade Agreements and the WTO”, Contemporary Asia Arbitration Journal, vol. 1, núm. 2, 2008.

Hamilton, Alexander, “The Judiciary Department”, Independent Journal, 1788.

Higgins, Rosalyn, "Respecting the Sovereign States and the Running a Tight Court-room”, International and Comparative Law Quarterly, 2001.

History of the ICSID Convention, http://icsid.worldbank.org/ICSID/FrontServ let ?request Type $=$ CasesRH\&action Val =Show Home\&pageName =AboutICSID_ Home.

KEBEDE TiBA, Firew, "What caused the multiplication of international Courts and Tribunals", Gonzaga Journal of International Law, vol. 10.

KingsburRY, Benedict, "Foreword: is the Proliferation of International Courts and Tribunals a Systemic Problem", International Law and Politics, vol. 31, 2003.

KlabBers, Jan et al., The Constitutionalization of International Law, Oxford University Press, 2011.

Koskenniemi, Martti y LeINO, Paivi, "Fragmentation of International Law: Post-Modern Anxieties”, Leiden Journal of International Law, vol. 15, 2005. La juridictionalisation du Droit International, Colloque de Lille, Société Francaise pour le Droit international, París, Pédone, 2003. 
OELLERS-FraHM, Karin, "Multiplication of International Courts and Tribunals and Conflicting Jurisdiction-Problems and Possible Solutions", Max Planck Institute for International and Comparative Law, UNYB, vol. 5, 2001.

PAuWElyn, Joost y SAlleS, Luiz Eduardo, "Forum Shopping Before International Tribunals: (Real) Concerns, (Im)possible Solutions”, Cornell International Law Journal, vol. 42, 2009.

PELlET, Allain, "Les fondements juridiques internationaux du droit communautaire", Recueil de cours de l'Académie de droit européen, vol. 5, 1994.

PROST, Mario y FOURET, Julien, "La multiplication des juridictions internationals: de la nécessité de remettre quelques pendules à l'heure", Revue Québécoise de Droit International, vol. 15.2, 2002.

RAO, Pemmaraju Sreenivasa, "Multiple Judicial Forums: a Reflections of the Growing Strengh of International Law or its Fragmentation”, Michigan Journal of International Law, vol. 25, 2004.

REED, Lucy, "Great Expectations: Where Does the Proliferation of International Dispute Resolution Tribunals Leave International Law?", American Society of International Law and Procedure, vol. 19, 2002.

Romano, Cesare, Project on International Courts and Tribunals, Trad. Omar Carrasco y Juan Andrés Alvarez, Center on International Cooperation, New York University, 2004-2005.

, "The Proliferation of International Judicial Bodies: the Pieces of the Puzzle", International Law and Politics, vol. 31, 1999.

, "The Shift from the Consensual to the Compulsory Paradigm in International Adjudication: Elements for a Theory of Consent”, International Law and Politics, vol. 39, 2007.

SEGRELLES, José Antonio, "Integración regional y globalización”, Terra livre, vol. 18, Sao Paolo, 2002.

SIMON, Denis, Le système juridique communautaire, 3a. ed., París, PUF, 2001. SHAnY, Yuval, "One Law to Rule Them All: Should International Courts be Viewed as Guardians of Procedural Order and Legal Uniformity?", en Fauchald, Ole Kristian y Nollkaemper, André (eds.), The Practice of International and National Courts and the (De-)Fragmentation of International Law, Hart Publishing, 2012.

, "No Longer a Weak Department of Power? Reflections on the Emergence of a New International Judiciary", European Journal of International Law, vol. 20, 2009. 
Stoll, Peter-Tobias y VDneKy, Silja, "The Swordfish Case: Law of the Sea v. Trade", Max Planck Institue foir International and Comparative Law, UNYB, 2000.

Swebel, Stephen, The Merits (and Demerits) of International Arbitration and Adjudication, Un Lecture Series, http://untreaty.un.org/cod/avl/ls/Schwe bel_CT_video_1.html.

TeUBnER, Gunther, Law as an Autopoeitic System, The European University Institute Press Series, 1993. , Global Law Without a State, Dartmouth, 1997.

VIRALly, Michel, Le droit international en devenir, PUF, 1990.

WeBB, Philippa, International Judicial Integration and Fragmentation, Oxford University Press, 2013. 